\title{
Economic Cross-Efficiency
}

\author{
Juan Aparicio ${ }^{\mathrm{a},{ }^{*}}$ and José L. Zofío \\ ${ }^{\text {a }}$ Center of Operations Research (CIO), Universidad Miguel Hernandez de Elche, E-03202 Elche, Alicante, \\ Spain. \\ ${ }^{\mathrm{b}}$ Department of Economics, Universidad Autónoma de Madrid, E-28049 Madrid, Spain. \\ Erasmus Research Institute of Management, Erasmus University, NL-3062PA, Rotterdam, The \\ Netherlands
}

\begin{abstract}
This paper is concerned with introducing a series of new concepts under the name of Economic Cross-Efficiency, which is rendered operational through Data Envelopment Analysis (DEA) techniques. To achieve this goal, from a theoretical perspective, we connect two key topics in the efficiency literature that have been unrelated until now: economic efficiency and cross-efficiency. In particular, it is shown that, under input (output) homotheticity, the traditional bilateral notion of input (output) cross-efficiency for unit $l$, when the weights of an alternative counterpart $k$ are used in the evaluation, coincides with the well-known Farrell notion of cost (revenue) efficiency for evaluated unit $l$ when the weights of $k$ are used as market prices. This motivates the introduction of the concept of Farrell Cross-Efficiency (FCE) based upon Farrell's notion of cost efficiency. One advantage of the FCE is that it is well defined under Variable Returns to Scale (VRS), yielding scores between zero and one in a natural way, and thereby improving upon its standard cross-efficiency counterpart. To complete the analysis we extend the FCE to the notion of Nerlovian cross-inefficiency (NCI), based on the dual relationship between profit inefficiency and the directional distance function. Finally, we illustrate the new models with a recently compiled dataset of European warehouses.
\end{abstract}

Keywords: Data Envelopment Analysis, Cross-efficiency, Farrell (Cost) Efficiency, Nerlove (Profit) Inefficiency, Warehousing.

\footnotetext{
*Corresponding author: J. Aparicio. Voice: +34 966658517; E-mail: j.aparicio@umh.es.
} 


\section{Introduction}

Data Envelopment Analysis (DEA) is a data-driven approach for estimating a piece-wise linear frontier enveloping from above a cloud of points in a space with dimensions associated with variables categorized as inputs and outputs. DEA is classified as a non-parametric and multidimensional technique, which is based on a few postulates (mainly convexity, free disposability and minimum extrapolation), and is usually used for assessing relative efficiencies of a homogeneous set of Decision Making Units (DMUs). Due to its flexibility and other advantages, in recent times, DEA has become one of the most used methodologies by researchers, practitioners and scholars in Operations Research, Economics and Engineering to estimate a best practice frontier in many different contexts. In particular, this technique allows determining an efficiency score for each evaluated unit, calculated as the distance from each DMU to the estimated frontier (see, for example, Petersen, 2018).

Regarding the determination of the distance to the frontier, it is worth mentioning that there exist in the DEA literature many different ways of implementing this idea of proximity; being the seminal and most used that associated with the radial models of Charnes et al. (1978) and Banker et al. (1984). In these models, defined as fractional linear programming formulations in its basic ratio-form, the technique allows DMUs to choose their own weights on inputs and outputs in order to maximize the ratio of a weighted sum of outputs to a weighted sum of inputs. In this manner, the assessed DMU is evaluated in the most favorable way and DEA provides a selfevaluation of the DMUs by using input and output weights that are unit-specific. Unfortunately, this flexibility that represents one of the distinctive landmarks of DEA makes it difficult to derive a suitable ordering of the units based on their efficiency score, as the best performing DMUs rank at the top with an efficiency score of one, all obtained with weights that are DMU-specific.

However, it is very common in real life that practitioners need to rank the set of assessed units with respect to their performance. One example is the famous Academic Ranking of World Universities (ARWU) — better known as the Shanghai Ranking, where over 1,200 universities are ranked according to six objective indicators every year. Other recent examples are the ranking of a list of journals using data from the Thomson Reuters Journal Citation Reports (JCR) (see Rosenthal and Weiss, 2017) or the ranking of countries participating in a sporting event as the Summer Olympic Games 2016 (see Jablonsky, 2018). This need has motivated the introduction into the DEA literature of different approaches for ranking the set of DMUs (Aldamak and Zolfaghari, 2017).

One of the most popular approaches for ranking units in DEA is that known as CrossEfficiency (CE) (Cook and Zhu, 2015; Ruiz and Sirvent, 2016). Cross-efficiency evaluation was originally introduced in Sexton et al. (1986) and popularized by Doyle and Green (1994). While 
DEA provides a self-evaluation for each DMU, using unit-specific optimal input and output weights, the cross-efficiency evaluation provides a peer-appraisal of the DMUs in which each unit is also assessed using the optimal DEA weights of the remaining observations. To be specific, this methodology relies on the weights of all the DMUs in the calculation of the so-called crossefficiencies, which again define as the usual ratio of a weighted sum of outputs to a weighted sum of inputs, but using the set of individual weights obtained for each one of the observed units. The final (multilateral) cross-efficiency scores of the different units are the average of their (bilateral) cross-efficiencies, and such scores can be used to rank the DMUs.

Whereas the ranking that we are determining through cross-efficiency is related to the notion of 'technical' efficiency, i.e., we are interested in evaluating the performance of a set of observations operating in a similar technological environment by comparing their activity with respect to the boundary enveloping the data; there exists another type of efficiency, with a more general meaning. We are referring to the concept of economic or overall efficiency, which is normally associated with the performance of 'for-profit' organizations when information on market prices are considered (e.g. firms operating within an industry). In market environments the measurement of, for example, cost efficiency is key to understand the competiveness of firms, Aparicio et al. (2015). These units are usually interested in changing the relative amounts of inputs (input mix) if this adjustment leads to real economic gains (i.e., given revenue, more profit through less cost). In particular, cost efficiency may be defined as how close the firm is to the optimal (minimum) feasible cost of producing a given amount of output. In a similar manner, we can find in the literature analogous definitions of revenue efficiency and profit efficiency.

Farrell (1957) was the first author in showing how to measure cost efficiency from the estimation of a best practice frontier, as the ratio between minimum cost and actual cost of a firm given input market prices. Additionally, he introduced a way of decomposing this overall measure into technical efficiency and allocative efficiency, as a means to understand what needs to be done to enhance the performance of the assessed unit. Technical efficiency measures how close the firm is to the frontier of the technology, whereas allocative efficiency measures the additional economic loss due to a sub-optimal input mix given market prices, once the firm is at the frontier. Moreover, under the Farrell approach, when the best practice frontier is estimated by DEA, the technical efficiency component coincides with the efficiency score linked to the (input-oriented) radial model by Charnes et al. (1978), in the case of assuming a constant returns to scale (CRS) technology, and by Banker et al. (1984), in the case of adopting variable returns to scale (VRS). It is worth mentioning that a revenue efficiency measure à la Farrell can be defined in an analogous way. 
In recent times, the interest of extending the ideas of Farrell to profit efficiency, instead of only cost or revenue efficiency, has resulted in the introduction in the literature of the so-called Nerlovian efficiency measure (Chambers et al., 1998). This approach defines profit inefficiency in an additive way and decomposes it into technical inefficiency and allocative inefficiency. Technical inefficiency is determined through the directional distance function, which is a graph measure in the sense that firms adjust both input and output quantities. As in the case of Farrell, the Nerlovian efficiency measure also uses the information of market prices to determine profit efficiency of each evaluated observation.

In spite of input and output weights determined by radial models in DEA being interpreted as prices-as shadow prices specifically (Lovell et al., 1994), cross-efficiency and economic efficiency are two independent topics in the literature that have evolved in parallel, without ever making a connection. Following this thread, this paper explores the existence of a common ground, making the connection between these two research fields by introducing the concept of Economic Cross-Efficiency and its application through DEA. In particular, we show that under the customary assumption of input (output) homotheticity, the traditional bilateral notion of input (output) cross-efficiency for unit $l$, when the weights of unit $k$ are used in the evaluation, coincides with the Farrell notion of cost (revenue) efficiency for unit $l$ when the weights of unit $k$ are used as market prices. This implies that, under homotheticity, the multilateral traditional crossefficiency notion matches the arithmetic mean of $n$ Farrell's cost efficiencies, where $n$ denotes the sample size. Additionally, we will show how to decompose in that case the standard crossefficiency into technical efficiency and (shadow) allocative efficiency.

The above result motivates the definition in a first instance of the concept of Farrell Economic Cross-Efficiency (FCE), based upon the notion of Farrell's cost efficiency. We prove that FCE coincides with standard cross-efficiency $(C E)$ in the context of production functions, i.e., when only an output is produced, under restrictive assumptions. One additional advantage of the FCE is that it easily allows the extension of the concept of cross-efficiency to technologies characterized by variable returns to scale (VRS), obtaining scores always between zero and one in a natural way, something that contrasts with the current cross-efficiency framework. This point is important in the context of cross-efficiency because the standard cross-efficiency measure under VRS presents the problem of negative values for some DMUs, unamenable to sensitive interpretation. However, many empirical situations require the assumption of VRS, for example when DMUs are of very different size (bank branches, universities, restaurants, etc.). This is the reason why some authors have tried to adapt the standard cross-efficiency to accommodate the need of using a VRS DEA model in order to avoid meaningless values (e.g., Wu et al., 2009, Lim and Zhu, 2015). 
To complete the analytical framework, once the Farrell approach $(F C E)$ has been introduced, we extend it to the wider case of profit inefficiency, by way of the notion of 'Nerlovian' crossinefficiency $(N C I)$. This allows us to deal with the general situation of simultaneous output and input adjustments through the directional distance function. Finally, we illustrate the new concepts and their associated models by calculating and decomposing the Farrell and Nerlovian economic cross-(in)efficiencies for a recently compiled dataset of European warehouses.

The paper is organized as follows. Section 2 is devoted to introduce the relationship between cross-efficiency and economic efficiency under homotheticity and to define the notion of Farrell (cost) cross efficiency under any returns to scale. In Section 3, we extend the Farrell crossefficiency to the context of graph measures by introducing the Nerlovian economic (profit) crossinefficiency measure. In Section 4 illustrates the applied feasibility of the models by reporting several numerical results using the warehouse dataset. Section 5 concludes.

\section{The Farrell economic (cost) cross-efficiency}

Let there be $m$ inputs, the (non-negative) quantities of which are measured by a vector $X \equiv\left(x_{1}, \ldots, x_{m}\right)$, and $s$ outputs, the (non-negative) quantities of which are measured by a vector $Y \equiv\left(y_{1}, \ldots, y_{s}\right)$. Given $n$ observed observations or DMUs, we have the set of data denoted as $\left\{\left(X_{k}, Y_{k}\right), k=1, \ldots, n\right\}$. The technology or production possibility set is defined, in general, as $T=\left\{(X, Y) \in R_{+}^{m+s}: X\right.$ can produce $\left.\mathrm{Y}\right\}$.

Using Data Envelopment Analysis, $T$ is estimated as $T_{c}=\left\{(X, Y) \in R_{+}^{m+s}: \sum_{j=1}^{n} \lambda_{j} x_{i j} \leq x_{i}, \forall i, \sum_{j=1}^{n} \lambda_{j} y_{r j} \geq y_{r}, \forall r, \lambda_{j} \geq 0, \forall j\right\}$ under constants returns to scale $(\mathrm{CRS}) \quad$ and $\quad$ as $\quad T_{v}=\left\{(X, Y) \in R_{+}^{m+s}: \sum_{j=1}^{n} \lambda_{j} x_{i j} \leq x_{i}, \forall i, \sum_{j=1}^{n} \lambda_{j} y_{r j} \geq y_{r}, \forall r, \sum_{j=1}^{n} \lambda_{j}=1, \lambda_{j} \geq 0, \forall j\right\} \quad$ under variable returns to scale (VRS) (Banker et al., 1984).

In DEA, for each DMU $k=1, \ldots, n$ the radial input technical efficiency assuming CRS is calculated through the following linear fractional programing problem (Charnes et al., 1978): 


$$
\begin{aligned}
& \operatorname{ITE}_{c}\left(X_{k}, Y_{k}\right)=\underset{U, V}{\operatorname{Max}} \frac{\sum_{r=1}^{s} u_{r} y_{r k}}{\sum_{i=1}^{m} v_{i} X_{i k}} \\
& \text { s.t. } \\
& \begin{array}{lll}
\frac{\sum_{r=1}^{s} u_{r} y_{r j}}{\sum_{i=1}^{m} v_{i} x_{i j}} \leq 1, & j=1, \ldots, n & \\
u_{r} \geq 0, & & \\
v_{i} \geq 0, & i=1, \ldots, s & (1.2) \\
& i=1, \ldots, m & (1.3)
\end{array}
\end{aligned}
$$

$\operatorname{ITE}_{c}\left(X_{k}, Y_{k}\right)$ always takes values between zero and one and its inverse coincides with the well-known Shephard input distance function in Economics (Shephard, 1953). Additionally, for computational purposes, model (1) can be easily linearized as:

$$
\begin{aligned}
& \operatorname{ITE}_{c}\left(X_{k}, Y_{k}\right)=\underset{U, V}{\operatorname{Max}} \sum_{r=1}^{s} u_{r} y_{r k} \\
& \text { s.t. } \quad \sum_{i=1}^{m} v_{i} x_{i k}=1, \\
& \sum_{r=1}^{s} u_{r} y_{r j}-\sum_{i=1}^{m} v_{i} x_{i j} \leq 0, \quad j=1, \ldots, n \\
& u_{r} \geq 0, \quad r=1, \ldots, s \\
& v_{i} \geq 0, \quad i=1, \ldots, m
\end{aligned}
$$

Any optimal solution of model (2) is an optimal solution of model (1). Moreover, the optimal value of model (2) coincides with the optimal value of model (1).

As we aforementioned, one drawback of radial input technical efficiencies is that they must not be used for ranking observations (Balk et al., 2017). To judge this, let $\left(V_{k}^{*}, U_{k}^{*}\right)$ be one of the possible optimal solutions of problem (2) and, therefore, of model (1). In this way, the comparison of the scores $I T E_{c}$ associated with two DMUs $k$ and $l$ involves not only their input and output quantities (as in standard bilateral productivity comparisons), but also two different profiles of shadow prices: $\left(V_{k}^{*}, U_{k}^{*}\right)$ and $\left(V_{l}^{*}, U_{l}^{*}\right)$.

$$
\operatorname{ITE}_{c}\left(X_{k}, Y_{k}\right) \geq \operatorname{ITE} E_{c}\left(X_{l}, Y_{l}\right) \Leftrightarrow \frac{\sum_{r=1}^{s} u_{r k}^{*} y_{r k}}{\sum_{i=1}^{m} v_{i k}^{*} X_{i k}} \geq \frac{\sum_{r=1}^{s} u_{r l}^{*} y_{r l}}{\sum_{i=1}^{m} v_{i l}^{*} X_{i l}} .
$$

Since usually $\left(V_{k}^{*}, U_{k}^{*}\right) \neq\left(V_{l}^{*}, U_{l}^{*}\right)$, it is discouraged to compare the performance of the two units by direct comparison of their scores. Instead, a cross-evaluation strategy is suggested in the 
literature (Sexton et al., 1986, and Doyle and Green, 1994). In particular, the (bilateral) cross input technical efficiency of unit $l$ with respect to unit $k$ is defined by

$$
\operatorname{CITE}_{c}\left(X_{l}, Y_{l} \mid k\right)=\frac{\sum_{r=1}^{s} u_{r k}^{*} y_{r l}}{\sum_{i=1}^{m} v_{i k}^{*} X_{i l}}
$$

$\operatorname{CITE}_{c}\left(X_{l}, Y_{l} \mid k\right)$ takes values between zero and one and satisfies $\operatorname{CITE}_{c}\left(X_{l}, Y_{l} \mid l\right)=\operatorname{ITE}_{c}\left(X_{l}, Y_{l}\right)$ [P1].

Given the observed $n$ units in the data sample, the traditional literature on cross-efficiency recommends to aggregate bilateral cross input technical efficiencies of unit $l$ with respect to all units $k, k=1, \ldots, n$, through the arithmetic mean to obtain the multilateral notion of cross input technical efficiency of unit $l$ :

$$
\operatorname{CITE}_{c}\left(X_{l}, Y_{l}\right)=\frac{1}{n} \sum_{k=1}^{n} \operatorname{CITE}_{c}\left(X_{l}, Y_{l} \mid k\right)=\frac{1}{n} \sum_{k=1}^{n} \frac{\sum_{r=1}^{s} u_{r k}^{*} y_{r l}}{\sum_{i=1}^{m} v_{i k}^{*} X_{i l}} .
$$

This measure satisfies several properties:

[P2] The greater $\operatorname{CITE}_{c}\left(X_{l}, Y_{l}\right)$, the better (meaning of efficiency);

[P3] $0 \leq \operatorname{CITE}_{c}\left(X_{l}, Y_{l}\right) \leq 1$;

[P4] If $\left(v_{k}^{*}, u_{k}^{*}\right)=\left(v_{l}^{*}, u_{l}^{*}\right), \forall k=1, \ldots, n$, then $\operatorname{CITE}_{c}\left(X_{l}, Y_{l}\right)=\operatorname{ITE}_{c}\left(X_{l}, Y_{l}\right)$;

[P5] $\operatorname{CITE}_{c}\left(X_{l}, Y_{l}\right)$ is units invariant.

Before bridging the gap between the above cross-efficiency literature and the economic efficiency literatures, we need to briefly recall the latter through the classical Farrell approach (Farrell, 1957). We start considering the Farrell radial paradigm for measuring and decomposing cost efficiency. For the sake of brevity, we state our discussion in the input space, defining the input requirement set $L(Y)$ as the set of non-negative inputs $X \in R_{+}^{m}$ that can produce non-negative output $Y \in R_{+}^{s}$, formally $L(Y)=\left\{X \in R_{+}^{N}:(\mathrm{X}, \mathrm{Y}) \in T\right\}$, and the isoquant of $L(Y): \operatorname{Isoq} L(Y)=$ $\{X \in L(Y): \varepsilon<1 \Rightarrow \varepsilon X \notin L(Y)\}$.

Let us also denote by $C_{L}(Y, W)$ the minimum cost of producing the output level $Y$ given the input market price vector $W \in R_{+}^{m}: C_{L}(Y, W)=\min \left\{\sum_{i=1}^{m} w_{i} x_{i}: X \in L(Y)\right\}$. 
The standard (multiplicative) Farrell approach views cost efficiency as originating from technical efficiency and allocative efficiency. Specifically, Farrell quantified, and therefore defined, each of these terms as follows:

$$
C E_{L}\left(X_{l}, Y_{l}\right)=\frac{C_{L}(Y, W)}{\underbrace{\sum_{i=1}^{m} w_{i} X_{i}}_{\text {Cost Efficiency }}}=\frac{1}{D_{L}(X, Y)} \cdot \underbrace{A E_{L}^{F}(X, Y ; W)}_{\text {Technical Efficiency }},
$$

where $D_{L}(X, Y)=\sup \{\delta>0: X / \delta \in L(Y)\}$ is the Shephard input distance function (Shephard, 1953) and allocative efficiency is defined residually as the ratio between cost efficiency and technical efficiency or, explicitly, as $A E_{L}^{F}(X, Y ; W)=\frac{C_{L}(Y, W)}{\sum_{i=1}^{m} w_{i}\left(\frac{x_{i}}{D_{L}(X, Y)}\right)}$. We will use the subscript $L$ to denote that we do not assume a specific type of returns to scale. Nevertheless, we will utilize $C_{c}(Y, W)$ and $D_{c}(X, Y)$ for CRS and $C_{v}(Y, W)$ and $D_{v}(X, Y)$ for VRS when needed. Additionally, it is well-known in Data Envelopment Analysis that the inverse of $D_{c}(X, Y)$ coincides with $\operatorname{ITE}_{c}\left(X_{k}, Y_{k}\right)$-program (1): $\operatorname{ITE}_{c}\left(X_{k}, Y_{k}\right)=D_{c}(X, Y)^{-1}$. Considering actual common market prices for all firms within an industry, then the natural way of comparing the performance of each one would be using the left-hand side in (6). We then could assess the obtained values for each firm since we were using the same reference weights (prices) for all the observations, creating a market based ranking.

Next, we are going to show that, under input homotheticity, the traditional bilateral notion of the cross input technical efficiency of unit $l$ with respect to unit $k, \operatorname{CITE}_{c}\left(X_{l}, Y_{l} \mid k\right)$, coincides with the Farrell notion of cost efficiency for unit $l$, i.e., the left-hand side in (6), when the input weights of unit $k, V_{k}^{*}=\left(v_{1 k}^{*}, \ldots, v_{m k}^{*}\right)$, are considered as input market prices. Nevertheless, we first recall the definition of input homotheticity (Jacobsen, 1970).

Definition 1. The technology $T$ is input homothetic if and only if $L(Y)=H(Y) \cdot L\left(1_{s}\right)$, where $H(Y): R^{s} \rightarrow R_{++}$and $1_{s}=(1, \ldots, 1) \in R^{s}$.

Input homotheticity is customarily assumed in empirical applications measuring overall economic efficiency because it ensures that radial reductions of inputs can be rightly interpreted as technical improvements resulting in cost savings. This is because, whatever the allocative efficiency magnitude resulting from the first order conditions for cost minimization-i.e., summarized in the (in)equality of marginal rates of substitution to input price ratios, it does not change along the radial contraction path represented by the input distance function. This result 
stems from one remarkable technological property normally taken for granted in the literature by customarily assuming homotheticity, that the marginal rates of substitution among inputs are independent of the output level, and therefore the radial contractions of input quantities leave allocative efficiency unchanged-see Proposition 2 in Aparicio and Zofío (2017:137). The geometric idea behind the notion of input homotheticity is that the input requirement sets for different output vectors along factor beams are "parallel" blown-ups (in contrast to Figure 1 where the map of isoquants corresponds to a non-homothetic technology). Given the advantages of assuming homotheticity among the most common technological properties, it comes as no surprise that it is routinely assumed by researchers, Chambers and Mitchell (2001).

The satisfaction of this property has relevant implications for this study in terms of the input requirement set and the cost function, which can be rewritten as follows (see Färe and Primont, 1995):

$$
\begin{gathered}
L(Y)=H(Y) L\left(1_{s}\right), \\
C_{L}(Y, W)=H(Y) C_{L}\left(1_{s}, W\right) .
\end{gathered}
$$

In order to prove the result that relates traditional cross-efficiency to Farrell's cost efficiency, we need to prove some previous results. We start showing the Linear Programming model that is used in DEA under CRS to determine the minimum cost, given the output level $Y_{l}$ and prices $V_{k}^{*}$ :

$$
\begin{aligned}
& C_{c}\left(Y_{l}, V_{k}^{*}\right)=\operatorname{Min}_{\lambda, X} \sum_{i=1}^{m} v_{i k}^{*} X_{i} \\
& \text { s.t. } \\
& -\sum_{j=1}^{n} \lambda_{j} x_{i j}+x_{i} \geq 0, \quad i=1, \ldots, m \\
& \sum_{j=1}^{n} \lambda_{j} y_{r j} \geq y_{r l}, \quad r=1, \ldots, s \quad(9.2) \\
& \lambda_{j} \geq 0, \quad j=1, \ldots, n \quad(9.3) \\
& x_{i} \geq 0, \quad i=1, \ldots, m \quad(9.4)
\end{aligned}
$$

In particular, under input homotheticity, expression (8) holds, and the optimal cost may be also determined through model (10) or by its dual, model (11): 


$$
\begin{aligned}
& C_{c}\left(Y_{l}, V_{k}^{*}\right)=H\left(Y_{l}\right) \quad \operatorname{Min}_{\lambda, X} \sum_{i=1}^{m} v_{i k}^{*} X_{i} \\
& \text { s.t. } \\
& -\sum_{j=1}^{n} \lambda_{j} x_{i j}+x_{i} \geq 0, \quad i=1, \ldots, m \\
& \sum_{j=1}^{n} \lambda_{j} y_{r j} \geq 1, \quad r=1, \ldots, s \\
& \lambda_{j} \geq 0, \quad j=1, \ldots, n \quad(10.3) \\
& x_{i} \geq 0, \quad i=1, \ldots, m \quad(10.4) \\
& C_{c}\left(Y_{l}, V_{k}^{*}\right)=H\left(Y_{l}\right) \quad \operatorname{Max}_{E, F} \sum_{r=1}^{s} e_{r} \\
& \text { s.t. } \\
& \sum_{r=1}^{s} e_{r} y_{r j}-\sum_{i=1}^{m} f_{i} x_{i j} \leq 0, \quad j=1, \ldots, n \\
& f_{i} \leq v_{i k}^{*}, \quad i=1, \ldots, m \\
& E \geq 0_{s}, F \geq 0_{m}
\end{aligned}
$$

Lemma 1. Let $\left(F^{*}, E^{*}\right)$ be an optimal solution of $(11)$. Then, $\left(V_{k}^{*}, E^{*}\right)$ is also an optimal solution of (11).

Proof. We first prove that $\left(V_{k}^{*}, E^{*}\right)$ is a feasible solution of (11). Constraints (11.2) and (11.3) trivially hold. Regarding (11.1), $\sum_{r=1}^{s} e_{r}^{*} y_{r j}-\sum_{i=1}^{m} v_{i k}^{*} x_{i j} \leq \sum_{r=1}^{s} e_{r}^{*} y_{r j}-\sum_{i=1}^{m} f_{i}^{*} x_{i j} \leq 0$ since $\left(F^{*}, E^{*}\right)$ satisfies (11.2) and (11.1). This implies that $\left(V_{k}^{*}, E^{*}\right)$ is a feasible solution of (11). As for the value of the objective function of (11), evaluated at $\left(V_{k}^{*}, E^{*}\right), \sum_{r=1}^{s} e_{r}^{*}$, it coincides with the optimal value of (11) . Therefore, $\left(V_{k}^{*}, E^{*}\right)$ is an optimal solution of (11).

Corollary 1. There always exists an optimal solution of model $(11),\left(F^{*}, E^{*}\right)$, with $F^{*}=V_{k}^{*}$.

Proof. This result is a direct consequence of Lemma 1.

Corollary 1, and given that $H\left(Y_{l}\right)$ does not depend on the decision variables $E$ and $F$, implies that $C_{c}\left(Y_{l}, V_{k}^{*}\right)$ can be computed as: 


$$
\begin{aligned}
& C_{c}\left(Y_{l}, V_{k}^{*}\right)=\operatorname{Max}_{E} \quad H\left(Y_{l}\right) \sum_{r=1}^{s} e_{r} \\
& \text { s.t. } \\
& \sum_{r=1}^{s} e_{r} y_{r j}-\sum_{i=1}^{m} v_{i k}^{*} x_{i j} \leq 0, \quad j=1, \ldots, n \\
& e_{r} \geq 0 \text {, } \\
& r=1, \ldots, s
\end{aligned}
$$

Now, we are ready to prove a key result in this paper: if $\left(V_{k}^{*}, U_{k}^{*}\right)$ is an optimal solution of model (2) then, under input-homotheticity, we have that the traditional (bilateral) cross input technical efficiency of unit $l$ with respect to unit $k$ coincides with Farrell notion of cost efficiency for unit $l$ when $V_{k}^{*}$ is used as input price, i.e., $\operatorname{CITE}_{c}\left(X_{l}, Y_{l} \mid k\right)=\frac{\sum_{r=1}^{s} u_{r k}^{*} y_{r l}}{\sum_{i=1}^{m} v_{i k}^{*} X_{i l}}=\frac{C_{c}\left(Y_{l}, V_{k}^{*}\right)}{\sum_{i=1}^{m} v_{i k}^{*} X_{i l}}$.

Theorem 1. Let $\left(V_{k}^{*}, U_{k}^{*}\right)$ be an optimal solution of model (2). If $T$ is input homothetic, then $\operatorname{CITE}_{c}\left(X_{l}, Y_{l} \mid k\right)=\frac{C_{c}\left(Y_{l}, V_{k}^{*}\right)}{\sum_{i=1}^{m} v_{i k}^{*} X_{i l}}$.

Proof. In particular, we need to prove that $\sum_{r=1}^{s} u_{r k}^{*} y_{r l}=C_{c}\left(Y_{l}, V_{k}^{*}\right)$. By (7), we have that $L(Y)=H(Y) L\left(1_{s}\right)$. Additionally, under Constant Returns to Scale, Färe and Primont (1995) show that $L(\delta Y)=\delta L(Y)$, for all $\delta>0$. Therefore, under both hypothesis, $L(Y)=L\left(H(Y) 1_{s}\right)$. In this way, we have that $\operatorname{ITE}_{c}\left(X_{k}, Y\right)^{-1}=D_{c}\left(X_{k}, Y\right)=\sup \left\{\delta>0: X_{k} / \delta \in L(Y)\right\}=$ $\sup \left\{\delta>0: X_{k} / \delta \in L\left(H(Y) 1_{s}\right)\right\}=I T E_{c}\left(X_{k}, H(Y) 1_{s}\right)^{-1}$ for any $Y \in R_{+}^{s}$. This result also implies that when we evaluate the input vector $X_{k}$ by means of the Shephard input distance function with respect to $L(Y)$, we get the same shadow prices than when we assess the input vector $X_{k}$ by means of the Shephard input distance function with respect to $L\left(H(Y) 1_{s}\right)$. Then, since we know that $\left(V_{k}^{*}, U_{k}^{*}\right)$ are shadow prices for unit $k$, i.e, it is an optimal solution of model (2), we have that $\left(V_{k}^{*}, U_{k}^{*}\right)$ is also an optimal solution of the following program: 


$$
\begin{array}{rll}
\operatorname{ITE}_{c}\left(X_{k}, Y_{k}\right)= & \underset{U, V}{\operatorname{Max}} & H\left(Y_{k}\right) \sum_{r=1}^{s} u_{r} \\
\text { s.t. } & \sum_{i=1}^{m} v_{i} x_{i k}=1, & \\
& \sum_{r=1}^{s} u_{r} y_{r j}-\sum_{i=1}^{m} v_{i} X_{i j} \leq 0, & j=1, \ldots, n \\
& u_{r} \geq 0, & r=1, \ldots, s \\
& v_{i} \geq 0, & i=1, \ldots, m
\end{array}
$$

By the same reasoning, the following two programs are equivalent with respect to optimal solutions and the optimal value:

$$
\begin{aligned}
& \operatorname{ITE}_{c}\left(X_{k}, H\left(Y_{l}\right) 1_{s}\right)=\underset{U, V}{\operatorname{Max}} H\left(Y_{l}\right) \sum_{r=1}^{s} u_{r} \\
& \text { s.t. } \quad \sum_{i=1}^{m} v_{i} x_{i k}=1 \text {, } \\
& \sum_{r=1}^{s} u_{r} y_{r j}-\sum_{i=1}^{m} v_{i} x_{i j} \leq 0, \quad j=1, \ldots, n \\
& u_{r} \geq 0, \quad r=1, \ldots, s \\
& v_{i} \geq 0, \quad i=1, \ldots, m \\
& \operatorname{ITE}_{c}\left(X_{k}, Y_{l}\right)=\underset{U, V}{\operatorname{Max}} \sum_{r=1}^{s} u_{r} y_{r l} \\
& \text { s.t. } \quad \sum_{i=1}^{m} v_{i} x_{i k}=1, \\
& \sum_{r=1}^{s} u_{r} y_{r j}-\sum_{i=1}^{m} v_{i} x_{i j} \leq 0, \quad j=1, \ldots, n \\
& u_{r} \geq 0, \quad r=1, \ldots, s \\
& v_{i} \geq 0, \quad i=1, \ldots, m
\end{aligned}
$$

Note that (13) and (14) are very similar. The difference is that $H\left(Y_{k}\right)$ has been substituted by $H\left(Y_{l}\right)$. Then, since the function $H(\cdot)$ does not depend on the decision variables $U, V$, we have that $\left(V_{k}^{*}, U_{k}^{*}\right)$ is an optimal solution of (14) and, consequently, optimal solution of (15). This implies that $\operatorname{ITE}_{c}\left(X_{k}, H\left(Y_{l}\right) 1_{s}\right)=\operatorname{ITE}\left(X_{k}, Y_{l}\right)=\sum_{r=1}^{s} u_{r k}^{*} y_{r l}$.

Finally, since $\left(V_{k}^{*}, U_{k}^{*}\right)$ is an optimal solution of (14) and $\sum_{i=1}^{m} v_{i k}^{*} x_{i k}=1$ by (2.1), we may compute (14) through (16). 


$$
\begin{array}{lll}
\underset{U}{\operatorname{Max}} & H\left(Y_{l}\right) \sum_{r=1}^{s} u_{r} \\
\text { s.t. } & \\
& \sum_{r=1}^{s} u_{r} y_{r j}-\sum_{i=1}^{m} v_{i k}^{*} x_{i j} \leq 0, \quad j=1, \ldots, n \\
& u_{r} \geq 0, & r=1, \ldots, s
\end{array}
$$

Program (16) coincides with (12). Hence, $C_{c}\left(Y_{l}, V_{k}^{*}\right)=\sum_{r=1}^{s} u_{r k}^{*} y_{r l}$

Theorem 1 implies that, under input-homotheticity, the 'traditional' multilateral notion of cross input technical efficiency of unit $l$ coincides with the arithmetic mean of $n$ Farrell's cost efficiencies, i.e.,

$$
\operatorname{CITE}_{c}\left(X_{l}, Y_{l}\right)=\frac{1}{n} \sum_{k=1}^{n} \operatorname{CITE}_{c}\left(X_{l}, Y_{l} \mid k\right)=\frac{1}{n} \sum_{k=1}^{n} \frac{C_{c}\left(Y_{l}, V_{k}^{*}\right)}{\sum_{i=1}^{m} v_{i k}^{*} X_{i l}} .
$$

In this way, under input-homotheticity traditional cross-efficiency can be reinterpreted in terms of Farrell's overall economic efficiency. This also implies that cross-efficiency could be easily decomposed into two components by applying (6):

$$
\begin{aligned}
& \operatorname{CITE}_{c}\left(X_{l}, Y_{l}\right)=\frac{1}{n} \sum_{k=1}^{n} \frac{C_{c}\left(Y_{l}, V_{k}^{*}\right)}{\sum_{i=1}^{m} v_{i k}^{*} X_{i l}}=\frac{1}{n} \sum_{k=1}^{n}\left[\frac{1}{D_{c}\left(X_{l}, Y_{l}\right)} \cdot A E_{c}^{F}\left(X_{l}, Y_{l} ; V_{k}^{*}\right)\right]= \\
& =\frac{1}{D_{c}\left(X_{l}, Y_{l}\right)} \cdot \frac{1}{n} \sum_{k=1}^{n} A E_{c}^{F}\left(X_{l}, Y_{l} ; V_{k}^{*}\right)=I T E_{c}\left(X_{l}, Y_{l}\right) \cdot \frac{1}{n} \sum_{k=1}^{n} A E_{c}^{F}\left(X_{l}, Y_{l} ; V_{k}^{*}\right) .
\end{aligned}
$$

Hence, under input homotheticity, cross-efficiency of unit $l$ can be seen as technical efficiency of unit $l$ times a 'correction' factor, associated with the arithmetic mean of $n$ (shadow) allocative efficiencies of unit $l$, each one calculated from the input shadow prices of unit $k$, $k=1, \ldots, n$.

Theorem 1 has also some interesting by-products. For example, in a DEA context where only an output is produced, i.e., when a production function is estimated, it can be proved that the 'traditional' multilateral notion of cross input technical efficiency always coincides with Farrell's notion of cost efficiency. It is worth mentioning that we do not need to adopt input homotheticity explicitly in the statement of the next corollary.

Corollary 2. Let $s=1$. Then, 


$$
\operatorname{CITE}_{c}\left(X_{l}, y_{l}\right)=\frac{1}{n} \sum_{k=1}^{n} \frac{C_{c}\left(y_{l}, V_{k}^{*}\right)}{\sum_{i=1}^{m} v_{i k}^{*} X_{i l}} .
$$

Proof. Aparicio et al. (2015) proved in their Proposition 3 that if $s=1$ and constant returns to scale are assumed, as happens in the computation of traditional cross-efficiency, then inputhomotheticity is satisfied. Finally, by Theorem 1, we have (19).

The above discussion, which relates traditional cross efficiency to a traditional measurement of overall efficiency, suggests that we could define cross-efficiency in DEA based on the notion of Farrell's cost efficiency, regardless of assuming or not input homotheticity. In this way, for a given set of reference prices (e.g., shadow prices, market prices or, even, other imputed prices), we define the Farrell cross-efficiency of unit $l$ with respect to unit $k$ as

$$
F C E_{L}\left(X_{l}, Y_{l} \mid k\right)=\frac{C_{L}\left(Y_{l}, V_{k}^{*}\right)}{\sum_{i=1}^{m} v_{i k}^{*} X_{i l}},
$$

where $L \in\{c, v\}$ denote constant and variable returns to scale.

As in (6), $F C E_{L}\left(X_{l}, Y_{l} \mid k\right)=\frac{1}{D_{L}\left(X_{l}, Y_{l}\right)} \cdot A E_{L}^{F}\left(X_{l}, Y_{l} ; V_{k}^{*}\right)$. Therefore, Farrell cross-efficiency of unit $l$ with respect to unit $k$ corrects the usual technical efficiency, the inverse of Shephard distance function, through a term with meaning of allocative efficiency.

In order to illustrate graphically the meaning of (20) and its decomposition, we resort to Figure 1. Let us assume that unit $l$ and unit $k$ are represented by points $\mathrm{D}$ and $\mathrm{A}$, respectively. Additionally, let us suppose that point D belongs to $L(1)$, while A belongs to $L(2)$. Then, first of all we need to solve the input-oriented radial model for point $\mathrm{A}$ in order to obtain its corresponding shadow prices. In this case, the projection point on the isoquant of $L(2)$ corresponds to point $\mathrm{B}$. The radial model also yields the rate of input substitution $-\left(v_{2}^{A} / v_{1}^{A}\right)$. Using the same rate of substitution, point $\mathrm{C}$ on the isoquant of $L(1)$ is determined. This is the point where the minimum cost is achieved on $L(1)$ according to $-\left(v_{2}^{A} / v_{1}^{A}\right)$. In this way, (20) corresponds to the ratio of the cost of $\mathrm{C}$ to the cost of $\mathrm{D}$. In Figure 1, this ratio is $0 \mathrm{~F} / 0 \mathrm{D}$. The score provided by (20) for unit D regarding unit $\mathrm{A}$ coincides with the traditional radial input technical efficiency, $0 \mathrm{E} / 0 \mathrm{D}$, whose calculation does not involve the (shadow) prices of unit A, modified by a correction term, which is $0 \mathrm{~F} / 0 \mathrm{E}$, i.e., the corresponding (shadow) allocative efficiency. 
Figure 1. Illustrating expression (20) and its decomposition.

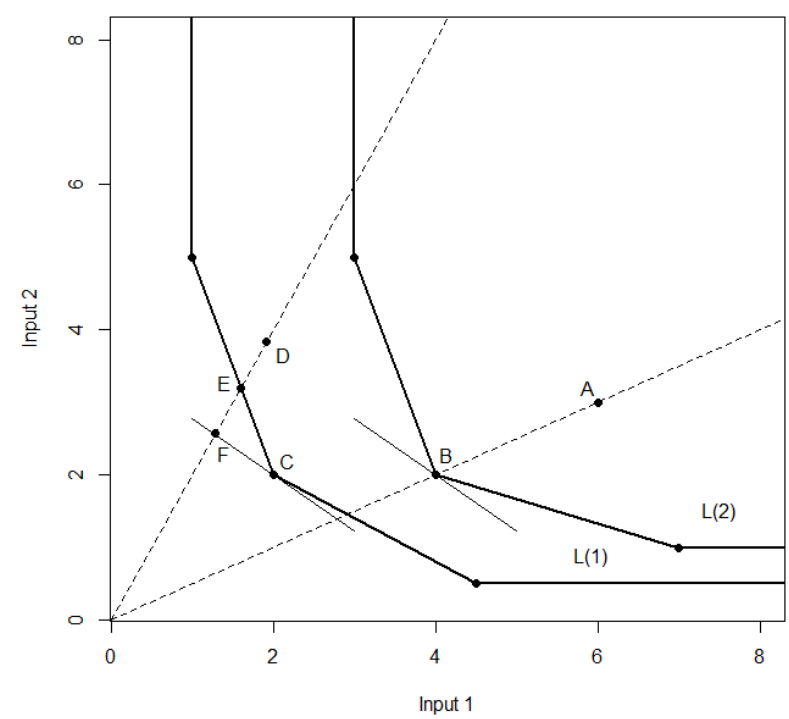

Given we have observed $n$ units in the data sample, the traditional literature on crossefficiency suggests to aggregate bilateral cross-efficiencies through the arithmetic mean to obtain the multilateral notion of cross efficiency. In the case of the Farrell cross-efficiency we have:

$$
F C E_{L}\left(X_{l}, Y_{l}\right)=\frac{1}{n} \sum_{k=1}^{n} F C E_{L}\left(X_{l}, Y_{l} \mid k\right)=\frac{1}{n} \sum_{k=1}^{n} \frac{C_{L}\left(Y_{l}, V_{k}^{*}\right)}{\sum_{i=1}^{m} v_{i k}^{*} X_{i l}} .
$$

Additionally, $\operatorname{FCE}_{L}\left(X_{l}, Y_{l}\right)$ can be always decomposed (under any returns to scale) into (radial) technical efficiency and a correction factor defined as the arithmetic mean of $n$ shadow allocative efficiency terms, as in expression (18). I.e.,

$$
\begin{aligned}
F C E_{L}\left(X_{l}, Y_{l}\right) & =\frac{1}{n} \sum_{k=1}^{n} F C E_{L}\left(X_{l}, Y_{l} \mid k\right)=\frac{1}{n} \sum_{k=1}^{n} \frac{C_{L}\left(Y_{l}, V_{k}^{*}\right)}{\sum_{i=1}^{m} v_{i k}^{*} X_{i l}}=\frac{1}{n} \sum_{k=1}^{n}\left[\frac{1}{D_{L}\left(X_{l}, Y_{l}\right)} \cdot A E_{L}^{F}\left(X_{l}, Y_{l} ; V_{k}^{*}\right)\right]= \\
& =\frac{1}{D_{L}\left(X_{l}, Y_{l}\right)} \cdot \frac{1}{n} \sum_{k=1}^{n} A E_{L}^{F}\left(X_{l}, Y_{l} ; V_{k}^{*}\right)=I T E_{L}\left(X_{l}, Y_{l}\right) \cdot \frac{1}{n} \sum_{k=1}^{n} A E_{L}^{F}\left(X_{l}, Y_{l} ; V_{k}^{*}\right),
\end{aligned}
$$

with $\operatorname{ITE}_{L}\left(X_{l}, Y_{l}\right)$ and $A E_{L}^{F}\left(X_{l}, Y_{l} ; V_{k}^{*}\right), L \in\{c, v\}$, denoting constant and variable returns to scale technical and allocative efficiencies, respectively.

Regarding the properties that this new notion of cross-efficiency satisfies, we next list the most important: 
[P1] $F C E_{L}\left(X_{l}, Y_{l} \mid l\right)=\frac{1}{D_{L}\left(X_{l}, Y_{l}\right)} ;$

[P2] The more $F C E_{L}\left(X_{l}, Y_{l}\right)$, the better (meaning of efficiency);

[P3] $0 \leq F C E_{L}\left(X_{l}, Y_{l}\right) \leq 1$;

[P4] If $\left(V_{k}^{*}, U_{k}^{*}\right)=\left(V_{l}^{*}, U_{l}^{*}\right), \forall k=1, \ldots, n$, then $F C E_{L}\left(X_{l}, Y_{l}\right)=\frac{1}{D_{L}\left(X_{l}, Y_{l}\right)}$;

[P5] $F_{C E}\left(X_{l}, Y_{l}\right)$ is units invariant;

[P6] If $\left(V_{k}^{*}, U_{k}^{*}\right)=(W, P), \forall k=1, \ldots, n$, then $F C E_{L}\left(X_{l}, Y_{l}\right)=C E_{L}\left(X_{l}, Y_{l}\right), \forall l=1, \ldots, n$.

Probably, the most remarkable property is P3 since it means that cross-efficiency is welldefined regardless of the assumed returns to scale. As was noted in the Introduction, this issue is critical in the context of cross-efficiency in DEA because the standard cross-efficiency measure under VRS presents the problem of negative values for some DMUs, representing a meaningless result. Almost the totality of the empirical applications involve a VRS characterization of the technology; for example when the units to be evaluated are universities with very different sizes (number of students, number of professors, budget, etc.). This is the reason why some authors have adapted the standard cross-efficiency to accommodate the need of using a VRS DEA model in order to avoid odd values (Wu et al., 2009, Lim and Zhu, 2015). In our case, we do not need to adapt/modify the FCE to fit well to different types of returns to scale. It accommodates variable returns to scale in a natural way by its definition.

Other important property is $\mathrm{P} 6$ since it means that, assuming for example perfect competition, the new approach collapses to the well-known Farrell measure of cost efficiency, which should be the standard reference to be used for evaluating performance and ranking units when information on a common set of prices, in this case market prices, is available. This property is not satisfied by the traditional notion of cross input technical efficiency in the literature, as $\operatorname{CITE}_{c}\left(X_{l}, Y_{l}\right)=\frac{1}{n} \sum_{k=1}^{n} \frac{\sum_{r=1}^{s} p_{r} y_{r l}}{\sum_{i=1}^{m} w_{i} x_{i l}}=\frac{\sum_{r=1}^{s} p_{r} y_{r l}}{\sum_{i=1}^{m} w_{i} x_{i l}}$, which is, in general, different from $C E_{c}\left(X_{l}, Y_{l}\right)=\frac{C_{c}\left(Y_{l}, W\right)}{\sum_{i=1}^{m} w_{i} X_{i l}}$

Next, we are going to prove another property, one that relates FCE and the traditional CITE under CRS, without assuming input homotheticity. The result states that $F C E_{c}\left(X_{l}, Y_{l}\right)$ is always an upper bound of $\operatorname{CITE}_{c}\left(X_{l}, Y_{l}\right)$. To prove that, we first need to introduce some additional notions. 
Given a vector of input and output prices $(W, P) \in R_{+}^{m+s}$, and a production possibility set $T$, the profit function $\Pi$ is defined as $\Pi_{T}(W, P)=\max _{x, y}\left\{\sum_{r=1}^{s} p_{r} y_{r}-\sum_{i=1}^{m} w_{i} x_{i}:(X, Y) \in T\right\}$. In particular, let $\Pi_{c}(W, P)$ be the way of denoting the optimal profit given $(W, P) \in R_{+}^{m+s}$ and the technology $T_{c}$.

Now, we prove that if $(W, P)=\left(V_{k}^{*}, U_{k}^{*}\right)$, where $\left(V_{k}^{*}, U_{k}^{*}\right)$ is an optimal solution of model (2), then $\Pi_{c}(W, P)=0$.

Lemma 2. Let $\left(V_{k}^{*}, U_{k}^{*}\right)$ be an optimal solution of (2), then $\Pi_{c}\left(V_{k}^{*}, U_{k}^{*}\right)=0$.

Proof. Under constant returns to scale, $\left(0_{m}, 0_{s}\right) \in T_{c}$. Therefore, $\Pi_{c}\left(V_{k}^{*}, U_{k}^{*}\right)$ must be greater or equal than zero by its definition. Let us assume that $\Pi_{c}\left(V_{k}^{*}, U_{k}^{*}\right)>0$. Then, there exists $(\hat{X}, \hat{Y}) \in T_{c}$ such that $\sum_{r=1}^{s} u_{r k}^{*} \hat{y}_{r}-\sum_{i=1}^{m} v_{i k}^{*} \hat{x}_{i}=\Pi_{c}\left(V_{k}^{*}, U_{k}^{*}\right)>0$. Regarding $(\hat{X}, \hat{Y})$, by the definition of $T_{c}=\left\{(X, Y) \in R_{+}^{m+s}: \sum_{j=1}^{n} \lambda_{j} x_{i j} \leq x_{i}, \forall i, \sum_{j=1}^{n} \lambda_{j} y_{r j} \geq y_{r}, \forall r, \lambda_{j} \geq 0, \forall j\right\}$, we know that there are $\hat{\lambda}_{1}, \ldots, \hat{\lambda}_{n} \geq 0$ such that $\sum_{j=1}^{n} \hat{\lambda}_{j} x_{i j} \leq \hat{x}_{i}, \quad i=1, \ldots, m$, and $\sum_{j=1}^{n} \hat{\lambda}_{j} y_{r j} \geq \hat{y}_{r}, \quad r=1, \ldots, s$. This implies that $\sum_{r=1}^{s} u_{r k}^{*} \hat{y}_{r}-\sum_{i=1}^{m} v_{i k}^{*} \hat{x}_{i} \leq \sum_{r=1}^{s} u_{r k}^{*}\left(\sum_{j=1}^{n} \hat{\lambda}_{j} y_{r j}\right)-\sum_{i=1}^{m} v_{i k}^{*}\left(\sum_{j=1}^{n} \hat{\lambda}_{j} x_{i j}\right)=\sum_{j=1}^{n} \hat{\lambda}_{j}^{\left(\sum_{r=1}^{s} u_{r k}^{*} y_{r j}-\sum_{i=1}^{m} v_{i k}^{*} x_{i j}\right)} \leq 0$, which is a contradiction. Hence, $\Pi_{c}\left(V_{k}^{*}, U_{k}^{*}\right)=0$.

Lemma 3. $\operatorname{CITE}_{c}\left(X_{l}, Y_{l} \mid k\right) \leq F C E_{c}\left(X_{l}, Y_{l} \mid k\right)$.

Proof. By the definitions of $\operatorname{CITE}_{c}\left(X_{l}, Y_{l} \mid k\right)$ and $\operatorname{FCE}_{c}\left(X_{l}, Y_{l} \mid k\right), \operatorname{CITE}_{c}\left(X_{l}, Y_{l} \mid k\right) \leq F C E_{c}\left(X_{l}, Y_{l} \mid k\right)$ is equivalent to $C_{c}\left(Y_{l}, V_{k}^{*}\right) \geq \sum_{r=1}^{s} u_{r k}^{*} y_{r l}$. So, we are going to prove that this second inequality holds. In this respect, Färe and Primont (1995, p. 136) showed that $\Pi_{T}(W, P)+C_{L}(Y, W) \geq \sum_{r=1}^{s} p_{r} y_{r}$, for all $(W, P) \in R_{+}^{m+s}$ and $Y \in R_{+}^{s}$. Let us assume CRS, $(W, P)=\left(V_{k}^{*}, U_{k}^{*}\right)$, where $\left(V_{k}^{*}, U_{k}^{*}\right)$ is an optimal solution of model (2), and $Y=Y_{l}$. Then, we have that $\Pi_{c}\left(V_{k}^{*}, U_{k}^{*}\right)+C_{c}\left(Y_{l}, V_{k}^{*}\right) \geq \sum_{r=1}^{s} u_{r k}^{*} y_{r l}$. Finally, by Lemma 2, $C_{c}\left(Y_{l}, V_{k}^{*}\right) \geq \sum_{r=1}^{s} u_{r k}^{*} y_{r l}$. 
Now, applying Lemma 3, we get the desired result.

Proposition 1. $\operatorname{CITE}_{c}\left(X_{l}, Y_{l}\right) \leq F C E_{c}\left(X_{l}, Y_{l}\right)$.

Finally, it is worth mentioning that analogous results can be derived for the cross output technical efficiency and revenue efficiency when output-homotheticity is assumed.

\section{The Nerlovian economic (profit) cross-inefficiency}

In this section, we extend the newly proposed notion of economic cross-efficiency, presented through the concept of Farrell cross-efficiency in the previous section, to the case of graph measures that accommodate both input and output variations. In particular, we introduce the notion of Nerlovian cross-inefficiency based upon the dual relationship between the Nerlovian profit inefficiency and the directional distance function, as presented by Chambers et al. (1998). Luenberger (1992) introduced the concept of benefit function as a representation of the amount that an individual is willing to trade, in terms of a specific reference commodity bundle $g$, for the opportunity to move from a consumption bundle to a utility threshold. Luenberger also defined a so-called shortage function (Luenberger, 1992, p. 242, Definition 4.1), which basically measures the distance in the direction of a vector $g$ of a production plan to the boundary of the production possibility set. In other words, the shortage function measures the amount by which a specific plan is short of reaching the frontier of the technology. In recent times, Chambers et al. (1998) redefined the benefit function and the shortage function as efficiency measures, introducing to this end the so-called directional distance function.

We will first need to introduce some notation.

Profit inefficiency à la Nerlove for a DMU $k$ is defined as optimal profit (i.e., the value of the profit function at the market prices) minus observed profit normalized by the value of a reference vector $\left(G_{k}^{x}, G_{k}^{y}\right) \in R_{+}^{m+s}: \frac{\Pi_{T}(W, P)-\left(\sum_{r=1}^{s} p_{r} y_{r k}-\sum_{i=1}^{m} w_{i} x_{i k}\right)}{\sum_{r=1}^{s} p_{r} g_{r k}^{y}+\sum_{i=1}^{m} w_{i} g_{i k}^{x}}$. Additionally, Chamber et al.

showed that profit inefficiency may be decomposed into technical inefficiency and allocative inefficiency, where technical inefficiency is in particular the directional distance function $\vec{D}_{T}\left(X_{k}, Y_{k} ; G_{k}^{x}, G_{k}^{y}\right)=\max \left\{\beta:\left(X_{k}-\beta G_{k}^{x}, Y_{k}+\beta G_{k}^{y}\right) \in T\right\}:$

$$
\frac{\Pi_{T}(W, P)-\left(\sum_{r=1}^{s} p_{r} y_{r k}-\sum_{i=1}^{m} w_{i} X_{i k}\right)}{\sum_{r=1}^{s} p_{r} g_{r k}^{y}+\sum_{i=1}^{m} w_{i} g_{i k}^{x}}=\vec{D}_{T}\left(X_{k}, Y_{k} ; G_{k}^{x}, G_{k}^{y}\right)+A I_{T}^{N}\left(X_{k}, Y_{k} ; W, P ; G_{k}^{x}, G_{k}^{y}\right) .
$$


use the subscript $T$ in $\Pi_{T}(W, P), \vec{D}_{T}\left(X_{k}, Y_{k} ; G_{k}^{x}, G_{k}^{y}\right)$ and $A I_{T}^{N}\left(X_{k}, Y_{k} ; W, P ; G_{k}^{x}, G_{k}^{y}\right)$ to denote that we do not assume a specific type of returns to scale. Nevertheless, we will utilize $\Pi_{c}(W, P)$, $\vec{D}_{c}\left(X_{k}, Y_{k} ; G_{k}^{x}, G_{k}^{y}\right)$ and $A I_{c}^{N}\left(X_{k}, Y_{k} ; W, P ; G_{k}^{x}, G_{k}^{y}\right)$ for CRS and $\Pi_{v}(W, P), \vec{D}_{v}\left(X_{k}, Y_{k} ; G_{k}^{x}, G_{k}^{y}\right)$ and $A I_{v}^{N}\left(X_{k}, Y_{k} ; W, P ; G_{k}^{x}, G_{k}^{y}\right)$ for VRS.

In the case of DEA, when CRS is assumed, the directional distance function for DMU $k$ is calculated through the following linear programming model:

$$
\begin{aligned}
\vec{D}_{c}\left(X_{k}, Y_{k} ; G_{k}^{x}, G_{k}^{y}\right)=\max _{\beta, \lambda} \beta & \\
\text { s.t. } & \\
& \sum_{j=1}^{n} \lambda_{j} x_{i j} \leq x_{i k}-\beta g_{i k}^{x}, \quad i=1, \ldots, m, \\
& \sum_{j=1}^{n} \lambda_{j} y_{r j} \geq y_{r k}+\beta g_{r k}^{y}, \quad r=1, \ldots, s, \\
& \lambda \geq 0_{n}
\end{aligned}
$$

Additionally, when VRS is assumed, then the directional distance function is determined through (24) for evaluating unit $k$.

$$
\begin{aligned}
\vec{D}_{v}\left(X_{k}, Y_{k} ; G_{k}^{x}, G_{k}^{y}\right)=\max _{\beta, \lambda} \beta & \\
\text { s.t. } & \\
& \sum_{j=1}^{n} \lambda_{j} x_{i j} \leq x_{i k}-\beta g_{i k}^{x}, \quad i=1, \ldots, m, \\
& \sum_{j=1}^{n} \lambda_{j} y_{r j} \geq y_{r k}+\beta g_{r k}^{y}, \quad r=1, \ldots, s, \\
& \sum_{j=1}^{n} \lambda_{j}=1, \\
\lambda \geq 0_{n} &
\end{aligned}
$$

In the particular case of the directional distance function under VRS, we are interested in showing its corresponding (linear) dual program (26).

$$
\begin{array}{ll}
\underset{U, V, \alpha}{\operatorname{Min}} & -\sum_{r=1}^{s} u_{r} y_{r k}+\sum_{i=1}^{m} v_{i} x_{i k}+\alpha \\
\text { s.t. } & \sum_{r=1}^{s} u_{r} y_{r j}-\sum_{i=1}^{m} v_{i} x_{i j}-\alpha \leq 0, \quad j=1, \ldots, n, \\
& \sum_{r=1}^{s} u_{r} g_{r k}^{y}+\sum_{i=1}^{m} v_{i} g_{i k}^{x}=1, \\
& U \geq 0_{s}, V \geq 0_{m}
\end{array}
$$

Let also denote one of the possible optimal solutions of problem (26) as $\left(\vec{V}_{k}^{*}, \vec{U}_{k}^{*}, \vec{\alpha}_{k}^{*}\right)$. 
Once we have introduced the desired notation, we define the Nerlovian cross-inefficiency of unit $l$ with respect to unit $k$. We consider initially the case of variable returns to scale DEA technologies and, subsequently, constant returns to scale production possibility sets. In this way, and inspired in the Farrell cross-efficiency notion introduced in the previous section when dealing with input-oriented models, we now suggest to consider the shadow prices for inputs and outputs of each unit $k,\left(\vec{V}_{k}^{*}, \vec{U}_{k}^{*}\right)$, as reference prices for evaluating the performance of unit $l$ through the left hand side of expression (23). So, we define the Nerlovian cross-inefficiency of unit $l$ with respect to unit $k$ as:

$$
\operatorname{NCI}_{T}\left(X_{l}, Y_{l} ; G_{l}^{x}, G_{l}^{y}, G_{k}^{x}, G_{k}^{y} \mid k\right)=\frac{\Pi_{T}\left(\vec{V}_{k}^{*}, \vec{U}_{k}^{*}\right)-\left(\sum_{r=1}^{s} \vec{u}_{r k}^{*} y_{r l}-\sum_{i=1}^{m} \vec{v}_{i k}^{*} x_{i l}\right)}{\sum_{r=1}^{s} \vec{u}_{r k}^{*} g_{r l}^{y}+\sum_{i=1}^{m} \vec{v}_{i k}^{*} g_{i l}^{x}} .
$$

On the one hand, it is worth mentioning that $N_{C I}\left(X_{l}, Y_{l} ; G_{l}^{x}, G_{l}^{y}, G_{k}^{x}, G_{k}^{y} \mid k\right)$ always takes values greater than zero since, by the definition of the profit function, $\Pi_{T}\left(\vec{V}_{k}^{*}, \vec{U}_{k}^{*}\right) \geq\left(\sum_{r=1}^{s} \vec{u}_{r k}^{*} y_{r l}-\sum_{i=1}^{m} \vec{v}_{i k}^{*} x_{i l}\right)$. On the other hand, the next proposition allow us to understand (27) in more detail under variable returns to scale.

Proposition 2. Let $\left(\vec{V}_{k}^{*}, \vec{U}_{k}^{*}, \vec{\alpha}_{k}^{*}\right)$ be an optimal solution of model (26). Then $\vec{\alpha}_{k}^{*}=\Pi_{v}\left(\vec{V}_{k}^{*}, \vec{U}_{k}^{*}\right)$.

Proof. (i) Let us first assume that $\vec{\alpha}_{k}^{*}>\Pi_{v}\left(\vec{V}_{k}^{*}, \vec{U}_{k}^{*}\right)$ Then, $\Pi_{v}\left(\vec{V}_{k}^{*}, \vec{U}_{k}^{*}\right)=\max _{x, y}\left\{\sum_{r=1}^{s} \vec{u}_{r k}^{*} y_{r}-\sum_{i=1}^{m} \vec{v}_{i k}^{*} X_{i}:(X, Y) \in T_{v}\right\} \geq \sum_{r=1}^{s} \vec{u}_{r k}^{*} y_{r j}-\sum_{i=1}^{m} \vec{v}_{i k}^{*} x_{i j} \quad$ for $\quad$ all $j=1, \ldots, n \quad$, since $\left(X_{j}, Y_{j}\right) \in T$. Therefore, $\left(\vec{V}_{k}^{*}, \vec{U}_{k}^{*}, \Pi_{v}\left(\vec{V}_{k}^{*}, \vec{U}_{k}^{*}\right)\right)$ is a feasible solution for (26). Regarding the objective function in (26), we have that $-\sum_{r=1}^{s} \vec{u}_{r}^{*} y_{r k}+\sum_{i=1}^{m} \vec{v}_{i}^{*} x_{i k}+\Pi\left(\vec{V}_{k}^{*}, \vec{U}_{k}^{*}\right)<-\sum_{r=1}^{s} \vec{u}_{r}^{*} y_{r k}+\sum_{i=1}^{m} \vec{v}_{i}^{*} x_{i k}+\vec{\alpha}_{k}^{*}$, which is a contradiction with the fact that $\left(\vec{V}_{k}^{*}, \vec{U}_{k}^{*}, \vec{\alpha}_{k}^{*}\right)$ is an optimal solution of (26). (ii) Let us now assume that $\vec{\alpha}_{k}^{*}<\Pi_{v}\left(\vec{V}_{k}^{*}, \vec{U}_{k}^{*}\right)$. Then, $\sum_{r=1}^{s} \vec{u}_{r}^{*} y_{r j}-\sum_{i=1}^{m} \vec{v}_{i}^{*} x_{i j} \leq \vec{\alpha}_{k}^{*}, \forall j=1, \ldots, n$, by the first set of constraints in (26). By the definition of the technology $T_{V}$, for all $(X, Y) \in T_{V}$ there exists a vector $\left(\lambda_{1}, \ldots, \lambda_{n}\right) \in R_{+}^{n}$ with $\sum_{j=1}^{n} \lambda_{j}=1$ such that $\sum_{r=1}^{s} \vec{u}_{r}^{*} y_{r}-\sum_{i=1}^{m} \vec{v}_{i}^{*} x_{i} \leq \sum_{r=1}^{s} \vec{u}_{r}^{*}\left(\sum_{j=1}^{n} \lambda_{j} y_{r j}\right)-\sum_{i=1}^{m} \vec{v}_{i}^{*}\left(\sum_{j=1}^{n} \lambda_{j} x_{i j}\right)=$ $\sum_{j=1}^{n} \lambda_{j}\left(\sum_{r=1}^{s} \vec{u}_{r}^{*} y_{r j}-\sum_{i=1}^{m} \vec{v}_{i}^{*} x_{i j}\right) \leq \vec{\alpha}_{k}^{*}<\Pi_{v}\left(\vec{V}_{k}^{*}, \vec{U}_{k}^{*}\right)$. Consequently, the maximum profit at prices 
$\left(\vec{V}_{k}^{*}, \vec{U}_{k}^{*}\right), \Pi_{v}\left(\vec{V}_{k}^{*}, \vec{U}_{k}^{*}\right)$, is not achieved by any point in $T_{V}$, which is a contradiction with polyhedral DEA technologies as is the case.

The above result implies that $\vec{\alpha}_{k}^{*}$ can be interpreted as shadow profit and, consequently, the Nerlovian cross-inefficiency for unit $l$ with respect to unit $k$ under VRS may be rewritten as

$$
N C I_{v}\left(X_{l}, Y_{l} ; G_{l}^{x}, G_{l}^{y}, G_{k}^{x}, G_{k}^{y} \mid k\right)=\frac{\vec{\alpha}_{k}^{*}-\left(\sum_{r=1}^{s} \vec{u}_{r k}^{*} y_{r l}-\sum_{i=1}^{m} \vec{v}_{i k}^{*} X_{i l}\right)}{\sum_{r=1}^{s} \vec{u}_{r k}^{*} g_{r l}^{y}+\sum_{i=1}^{m} \vec{v}_{i k}^{*} g_{i l}^{x}} .
$$

The arithmetic mean of (27) over all observed units yields the final score for firm l:

$$
\begin{gathered}
N C I_{T}\left(X_{l}, Y_{l} ;\left\{G_{k}^{x}, G_{k}^{y}\right\}_{k=1}^{n}\right)=\frac{1}{n} \sum_{k=1}^{n} N C I_{T}\left(X_{l}, Y_{l} ; G_{l}^{x}, G_{l}^{y}, G_{k}^{x}, G_{k}^{y} \mid k\right)= \\
=\frac{1}{n} \sum_{k=1}^{n} \frac{\Pi_{T}\left(\vec{V}_{k}^{*}, \vec{U}_{k}^{*}\right)-\left(\sum_{r=1}^{s} \vec{u}_{r k}^{*} y_{r l}-\sum_{i=1}^{m} \vec{v}_{i k}^{*} X_{i l}\right)}{\sum_{r=1}^{s} \vec{u}_{r k}^{*} g_{r l}^{y}+\sum_{i=1}^{m} \vec{v}_{i k}^{*} g_{i l}^{x}} .
\end{gathered}
$$

Invoking (23), we get that the Nerlovian cross-inefficiency of firm $l$ is a 'correction' of the original directional distance function value for this unit, where the modification factor can be interpreted as (shadow) allocative inefficiency:

$$
N C I_{T}\left(X_{l}, Y_{l} ;\left\{G_{k}^{x}, G_{k}^{y}\right\}_{k=1}^{n}\right)=\vec{D}_{T}\left(X_{0}, Y_{0} ; G_{l}^{x}, G_{l}^{y}\right)+\frac{1}{n} \sum_{k=1}^{n} A I_{T}^{N}\left(X_{l}, Y_{l} ; \vec{V}_{k}^{*}, \vec{U}_{k}^{*} ;\left\{G_{k}^{x}, G_{k}^{y}\right\}_{k=1}^{n}\right)
$$

Regarding the properties that the Nerlovian cross-inefficiency satisfies, we next list the most important ones.

[P1] $N C I_{T}\left(X_{l}, Y_{l} ; G_{l}^{x}, G_{l}^{y}, G_{l}^{x}, G_{l}^{y} \mid l\right)=\vec{D}_{T}\left(X_{l}, Y_{l} ; G_{l}^{x}, G_{l}^{y}\right)$;

[P2] The less $\operatorname{NCI}_{T}\left(X_{l}, Y_{l} ;\left\{G_{k}^{x}, G_{k}^{y}\right\}_{k=1}^{n}\right)$, the better (meaning of inefficiency);

[P3] $\operatorname{NCI}_{T}\left(X_{l}, Y_{l} ;\left\{G_{k}^{x}, G_{k}^{y}\right\}_{k=1}^{n}\right) \geq 0$;

[P4] If $\left(\vec{V}_{k}^{*}, \vec{U}_{k}^{*}\right)=\left(\vec{V}_{l}^{*}, \vec{U}_{l}^{*}\right), \forall k=1, \ldots, n$, then $\operatorname{NCI}_{T}\left(X_{l}, Y_{l} ;\left\{G_{k}^{x}, G_{k}^{y}\right\}_{k=1}^{n}\right)=\vec{D}_{T}\left(X_{l}, Y_{l} ; G_{l}^{x}, G_{l}^{y}\right)$;

[P5] If $\left(G_{k}^{x}, G_{k}^{y}\right), k=1, \ldots, n$, depends on data, then $\operatorname{NCI}_{T}\left(X_{l}, Y_{l} ;\left\{G_{k}^{x}, G_{k}^{y}\right\}_{k=1}^{n}\right)$ is units invariant;

[P6] If $\left(G_{k}^{x}, G_{k}^{y}\right), k=1, \ldots, n$, depends on data, then $\operatorname{NCI}_{T}\left(X_{l}, Y_{l} ;\left\{G_{k}^{x}, G_{k}^{y}\right\}_{k=1}^{n}\right)$ is price invariant. 
As we are aware, there is only an attempt to extend the notion of the traditional crossefficiency $\operatorname{CITE}_{c}\left(X_{l}, Y_{l}\right)$ to the world of non-oriented measures, i.e., which account for the inefficiency both in inputs and in outputs simultaneously. In particular, Ruiz (2013) extended the cross-efficiency evaluation theory for use with the directional distance function. Specifically, this author considered the directional vector equal to the assessed observation, i.e., $\left(G_{k}^{x}, G_{k}^{y}\right)=\left(X_{k}, Y_{k}\right)$ for all $k=1, \ldots, n$ in (24), and, as usual in cross-efficiency evaluation, he also assumed constant returns to scale,

Ruiz (2013), assuming CRS and $\left(G^{x}, G^{y}\right)=\left(X_{k}, Y_{k}\right)$, defined the cross DDF inefficiency of firm $l$ with respect to firm $k$ as (Ruiz, 2013, Definition 1, p. 183):

$$
\operatorname{CDDF}_{c}\left(X_{l}, Y_{l} \mid k\right)=\frac{\sum_{i=1}^{m} \vec{v}_{i k}^{*} X_{i l}-\sum_{r=1}^{s} \vec{u}_{r k}^{*} y_{r l}}{\sum_{i=1}^{m} \vec{v}_{i k}^{*} X_{i l}+\sum_{r=1}^{s} \vec{u}_{r k}^{*} y_{r l}}
$$

As in the radial case, Ruiz (2013) suggested averaging the $n$ values of the $C D D F_{c}\left(X_{l}, Y_{l} \mid k\right)$, $k=1, \ldots, n$, in order to define the DDF cross-efficiency of firm $l$ :

$$
C D D F_{c}\left(X_{l}, Y_{l}\right)=\frac{1}{n} \sum_{k=1}^{n} C D D F_{c}\left(X_{l}, Y_{l} \mid k\right)=\frac{1}{n} \frac{\sum_{i=1}^{m} \vec{v}_{i k}^{*} x_{i l}-\sum_{r=1}^{s} \vec{u}_{r k}^{*} y_{r l}}{\sum_{i=1}^{m} \vec{v}_{i k}^{*} x_{i l}+\sum_{r=1}^{s} \vec{u}_{r k}^{*} y_{r l}} .
$$

Next, we show that the cross-efficiency based on the DDF under CRS, is a particular case of a more general approach based upon the Nerlovian inefficiency measure; notion related, by duality, to the DDF.

It is possible to define a Nerlovian cross-inefficiency measure under constant returns to scale resorting to expression (28). To do that, it is enough to substitute $\vec{\alpha}_{k}^{*}$ by zero in (28) since this is the value of the shadow profit under CRS (see Lemma 2). If, additionally, we fix $\left(G_{k}^{x}, G_{k}^{y}\right)=\left(X_{k}, Y_{k}\right)$ for all $k=1, \ldots, n$, then we get:

$$
N C I_{c}\left(X_{l}, Y_{l} ; X_{l}, Y_{l}, X_{k}, Y_{k} \mid k\right)=\frac{-\left(\sum_{r=1}^{s} \vec{u}_{r k}^{*} y_{r l}-\sum_{i=1}^{m} \vec{v}_{i k}^{*} x_{i l}\right)}{\sum_{r=1}^{s} \vec{u}_{r k}^{*} y_{r l}+\sum_{i=1}^{m} \vec{v}_{i k}^{*} X_{i l}}=\frac{\sum_{i=1}^{m} \vec{v}_{i k}^{*} X_{i l}-\sum_{r=1}^{s} \vec{u}_{r k}^{*} y_{r l}}{\sum_{i=1}^{m} \vec{v}_{i k}^{*} X_{i l}+\sum_{r=1}^{s} \vec{u}_{r k}^{*} y_{r l}}=C D D F_{c}\left(X_{l}, Y_{l} \mid k\right) .
$$

And, finally, taking the mean over all the units in the sample, we obtain that the Nerlovian approach coincides with the cross-inefficiency defined by Ruiz (2013) based on the directional 
distance function under CRS. Moreover, it can be decomposed likewise into the (directional) technical inefficiency and a correction factor defined as the arithmetic mean of $n$ shadow allocative efficiency terms, as in expression (30). I.e.,

$$
N C I_{c}\left(X_{l}, Y_{l} ;\left\{X_{k}, Y_{k}\right\}_{k=1}^{n}\right)=\vec{D}_{c}\left(X_{l}, Y_{l} ; X_{l}, Y_{l}\right)+\frac{1}{n} \sum_{k=1}^{n} A I_{c}^{N}\left(X_{l}, Y_{l} ; \vec{V}_{k}^{*}, \vec{U}_{k}^{*} ;\left\{X_{k}, Y_{k}\right\}_{k=1}^{n}\right) .
$$

\section{Empirical application to warehousing data}

To illustrate the new concept of economic cross-(in)efficiency and its empirical implementation, we rely on a database on 102 warehouses operating in the Benelux area recently compiled by Balk et al. (2017) for 2017-see their section 4 for specific details on survey methods, sample size, and final dataset. Following these authors, as well as previous studies by De Koster and Balk (2008) and Johnson and McGinnis (2011), we characterize the production technology in terms of the following three inputs and four outputs. Inputs are: I.1) Warehouse size in $\mathrm{m} 2$ (Floor space); I.2) Number of full time equivalent employees (FTEs); and I.3) Number of stock keeping units (SKUs). On the output side the following variables are considered: O.1) Number of order lines (Order lines shipped per day); O.2) Error-free order line percentage (Error free \%); O.3) Order flexibility (per day); and O.4) Number of special processes (handled per day). Table 1 shows the descriptive statistics for all selected variables.

Table 1. Descriptive statistics for inputs and outputs, warehouse data, 2017.

\begin{tabular}{lccc|cccc} 
& \multicolumn{3}{c|}{ Inputs } & \multicolumn{5}{c}{ Outputs } \\
\cline { 2 - 8 } & $\begin{array}{c}\text { Floor } \\
\text { space }\end{array}$ & FTEs & SKUs & $\begin{array}{c}\text { Order } \\
\text { lines }\end{array}$ & $\begin{array}{c}\text { Error } \\
\text { free }\end{array}$ & $\begin{array}{c}\text { Order } \\
\text { flexibility }\end{array}$ & $\begin{array}{c}\text { Special } \\
\text { processes }\end{array}$ \\
\hline Minimum & 500 & 50 & 100 & 54 & 1 & 12 & 2 \\
Median & 9,250 & 30 & 4,600 & 1,200 & 7 & 22 & 6 \\
Average & 18,244 & 59 & 21,088 & 4,931 & 6 & 21 & 6 \\
Maximum & 275,000 & 350 & 400,000 & 55,000 & 9 & 30 & 10 \\
Stand. Dev. & 32,414 & 74 & 57,393 & 9,815 & 2 & 4 & 2 \\
\hline
\end{tabular}

Source: Balk et al. (2017).

\subsection{Farrell economic (cost) cross-efficiency}

Table 2 reports the results for the original Farrell input oriented model that radially measures technical efficiency for warehouse $l$ as in $(1), \operatorname{ITE}_{c}\left(X_{l}, Y_{l}\right)$, its standard technical cross-efficiency measure (5), $\operatorname{CITE}_{c}\left(X_{l}, Y_{l}\right)$, and the new Farrell cost cross-efficiency measure (21), $\operatorname{FCE}_{c}\left(X_{l}, Y_{l}\right)$. Also, following the proposed decomposition, we also report the allocative efficiency associated 
to the new cross-efficiency measure, calculated as the ratio between $\operatorname{CITE}_{c}\left(X_{l}, Y_{l}\right)$ and $\operatorname{ITE}_{c}\left(X_{l}, Y_{l}\right)$; i.e., expression (22). The first set of results corresponds to the existing setting in the literature corresponding to constant returns to scale (CRS). These are grouped under that heading on the left hand side of Table $2 .^{1}$

The results for the five best and worst performing warehouses are ranked using the values of the new Farrell economic cross-efficiency measure, $\operatorname{FCE}_{c}\left(X_{l}, Y_{l}\right)$. First we focus on the comparison between this latter measure and the standard cross-efficiency measure $\operatorname{CITE}_{c}\left(X_{l}, Y_{l}\right)$ . The individual values show that both cross-efficiency measures have the capability of discriminating between radially efficient observations with $\operatorname{ITE}_{c}\left(X_{l}, Y_{l}\right)=1$. However, the ranking exhibits some variability. For example, warehouse \#33, ranking first according to the cost cross-efficiency measure: $F_{C} E_{c}\left(X_{l}, Y_{l}\right)=0.960$, ranks below the fifth position according to $\operatorname{CITE}_{c}\left(X_{l}, Y_{l}\right)=0.667$. On the lower tail of the distribution there seems to be larger compatibility as the worst five performing warehouses exhibit the same ordering.

Throughout this empirical section we discuss the (dis)similarity between alternative crossefficiency measures by studying their ranking compatibility by means of the Spearman correlation and, relying on kernel density estimations, by determining whether their distributions are equal or not according to the $\mathrm{Li}$ tests. When plotting the kernel density functions we follow the procedure proposed by Simar and Zelenyuk (2006), which in short: (i) uses Gaussian kernels, (ii) employs the reflection method to overcome the issue of (radial) unitary or (directional) zero bounded supports for the cross-(in)efficiency scores (Silverman, 1986), and (iii) determines the bandwidths using Sheather and Jones (1991) method. Subsequently, once the kernel density functions are calculated we apply the nonparametric test developed by Li (1996) to determine if they are statistically different. Here we again follow Simar and Zelenyuk (2006) and use algorithm II with 1,000 replications, which computes the Li statistic on the bootstrapped estimates of the DEA scores, and where the unitary or null values of the efficient observations are smoothed by adding a small noise. These different dimensions will allow us to establish statistically to what extend the alternative cross-efficiency measures lead to equal or different results regarding warehouse performance.

\footnotetext{
${ }^{1}$ For input-oriented radial measures, the greater the score the higher the efficiency.
} 
Table 2. Farrell cost cross-efficiency decomposition, $F C E_{L}$. Expression (21), $L \in\{c, v\}$, CRS and VRS, respectively.

\begin{tabular}{|c|c|c|c|c|c|c|c|c|c|}
\hline \multirow[b]{2}{*}{ Ranking } & \multicolumn{5}{|c|}{ Constant Returns to Scale, CRS (CCR model, input orientation) } & \multicolumn{4}{|c|}{ Variable Returns to Scale, VRS (BCC model, input orientation) } \\
\hline & $\begin{array}{c}\text { Warehouse } \\
\#\end{array}$ & $\begin{array}{c}\text { Standard ITE } \\
\operatorname{ITE}_{c}\left(X_{l}, Y_{l}\right) \\
(1)\end{array}$ & $\begin{array}{c}\text { Standard } \\
\text { Cross-Effic. } \\
\operatorname{CITE}_{c}\left(X_{l}, Y_{l}\right) \\
(5) \\
\end{array}$ & $\begin{array}{c}\text { New Farrell } \\
\text { Cross- Effic. } \\
F C E_{c}\left(X_{l}, Y_{l}\right) \\
(21) \\
\end{array}$ & $\begin{array}{c}\text { New Farrell } \\
\text { Alloc. Efficiency } \\
F C E_{c}\left(X_{l}, Y_{l}\right) / I^{\prime} E_{c}\left(X_{l}, Y_{l}\right) \\
(22) \\
\end{array}$ & $\begin{array}{c}\text { Warehouse } \\
\quad \#\end{array}$ & $\begin{array}{l}\text { Standard ITE } \\
\operatorname{ITE}_{v}\left(X_{l}, Y_{l}\right)\end{array}$ & $\begin{array}{c}\text { New Farrell } \\
\text { Cross Effic. } \\
\operatorname{FCE}_{v}\left(X_{l}, Y_{l}\right) \\
(21) \\
\end{array}$ & $\begin{array}{c}\text { New Farrell } \\
\text { Alloc. Effic. } \\
F C E_{v}\left(X_{l}, Y_{l}\right) / I T E_{v}\left(X_{l}, Y_{l}\right) \\
(22) \\
\end{array}$ \\
\hline 1 & 33 & 1.000 & 0.667 & 0.960 & 0.960 & 19 & 1.000 & 1.000 & 1.000 \\
\hline 2 & 19 & 1.000 & 0.812 & 0.908 & 0.908 & 33 & 1.000 & 1.000 & 1.000 \\
\hline 3 & 50 & 1.000 & 0.819 & 0.898 & 0.898 & 36 & 1.000 & 1.000 & 1.000 \\
\hline 4 & 54 & 1.000 & 0.682 & 0.890 & 0.890 & 42 & 1.000 & 1.000 & 1.000 \\
\hline 5 & 49 & 1.000 & 0.757 & 0.818 & 0.818 & 45 & 1.000 & 1.000 & 1.000 \\
\hline 98 & 11 & 0.118 & 0.059 & 0.069 & 0.585 & 9 & 0.213 & 0.072 & 0.338 \\
\hline 99 & 12 & 0.153 & 0.056 & 0.064 & 0.418 & 69 & 0.107 & 0.070 & 0.654 \\
\hline 100 & 69 & 0.106 & 0.042 & 0.063 & 0.594 & 12 & 0.155 & 0.066 & 0.426 \\
\hline 101 & 65 & 0.101 & 0.029 & 0.039 & 0.386 & 65 & 0.117 & 0.041 & 0.350 \\
\hline \multirow[t]{6}{*}{102} & 77 & 0.051 & 0.023 & 0.034 & 0.667 & 77 & 0.053 & 0.037 & 0.698 \\
\hline & Minimum & 0.051 & 0.023 & 0.034 & 0.229 & Minimum & 0.053 & 0.037 & 0.223 \\
\hline & Median & 0.411 & 0.180 & 0.224 & 0.605 & Median & 0.622 & 0.371 & 0.606 \\
\hline & Average & 0.484 & 0.233 & 0.283 & 0.582 & Average & 0.662 & 0.443 & 0.631 \\
\hline & Maximum & 1.000 & 0.819 & 0.960 & 0.960 & Maximum & 1.000 & 1.000 & 1.000 \\
\hline & Stand. Dev. & 0.294 & 0.176 & 0.210 & 0.144 & Stand. Dev. & 0.314 & 0.306 & 0.202 \\
\hline
\end{tabular}


We may now establish the similarity between the new Farrell cost cross-efficiency measure and its standard counterpart starting with their ranking compatibility. Their Spearman correlation is $\rho\left(\operatorname{CITE}_{c}\left(X_{l}, Y_{l}\right), F C E_{c}\left(X_{l}, Y_{l}\right)\right)=0.988$, which is significant at the $1 \%$ level. This result implies that beyond individual disparities, both series yield a very similar picture of the warehouse industry standing. This can be clearly visualized in Figure 2 by comparing their kernel density functions, whose patterns closely follow each other, and is further corroborated by the Li-test comparing $\operatorname{CITE}_{c}\left(X_{l}, Y_{l}\right)$ vs. $F C E_{c}\left(X_{l}, Y_{l}\right)$ (i.e., -0.735 ), whose result does not allow to reject the null hypothesis of the equality of distributions, as reported in Table 3.

Figure 2. Estimated kernel density distributions of the standard, $\operatorname{CITE}_{c}\left(X_{l}, Y_{l}\right)-(5)$, and new Farrell economic cross-efficiencies: $F C E_{c}\left(X_{l}, Y_{l}\right)-(21)$ (under CRS), and $F C E_{v}\left(X_{l}, Y_{l}\right)-(21)$ (under VRS).

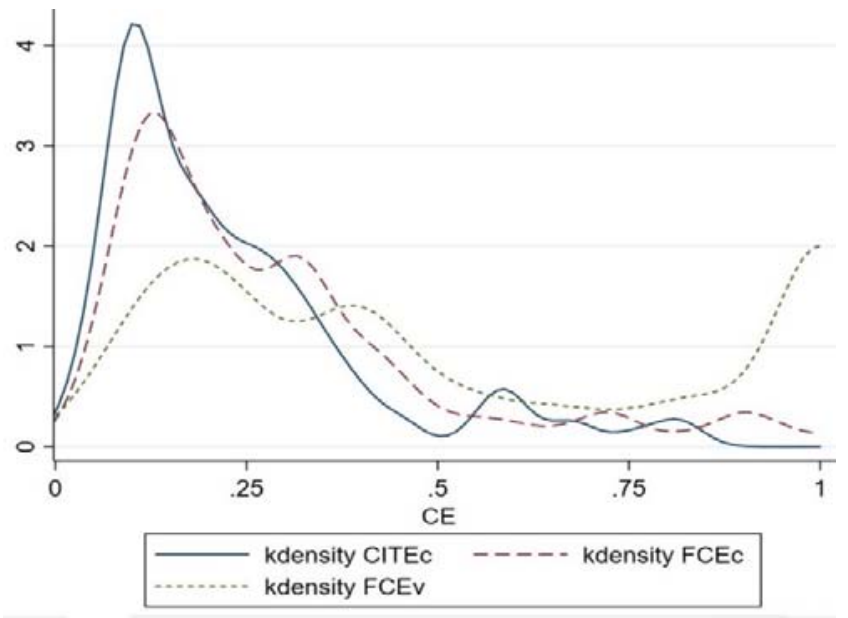

Table 3. Results of Simar and Zelenyuk (2006) adapted Li test (test statistic and significance level).

\begin{tabular}{l|c|c|c|c} 
& $\operatorname{CITE}_{c}\left(X_{l}, Y_{l}\right)$ & $\operatorname{CITE}_{c}\left(X_{l}, Y_{l}\right)$ & $F C E_{c}\left(X_{l}, Y_{l}\right)$ & $N C I_{v}\left(X_{l}, Y_{l} ;\left\{X_{k}, Y_{k}\right\}_{k=1}^{n}\right)$ \\
& vs & vs & vs \\
& $F C E_{c}\left(X_{l}, Y_{l}\right)$ & $F C E_{v}\left(X_{l}, Y_{l}\right)$ & $F C E_{v}\left(X_{l}, Y_{l}\right)$ & $\operatorname{CDDF}_{c}\left(X_{l}, Y_{l}\right)$ \\
\hline Statistic & -0.735 & $6.257^{*}$ & $2.056^{*}$ & $15.245^{*}$ \\
$p$ value & $(0.220)$ & $(0.000)$ & $(0.000)$ & $(0.000)$ \\
\hline
\end{tabular}

Notes: $\operatorname{CITE}_{c}\left(X_{l}, Y_{l}\right),(5) ; F_{C E}\left(X_{l}, Y_{l}\right),(21)$-under CRS; $F C E_{v}\left(X_{l}, Y_{l}\right),(21)$-under VRS.

$\operatorname{NCI}_{v}\left(X_{l}, Y_{l} ;\left\{X_{k}, Y_{k}\right\}_{k=1}^{n}\right),(29) ; \operatorname{CDDF}_{c}\left(X_{l}, Y_{l}\right),(32)$.

* Denotes statistically significant differences between models at the critical 1 percent level. 
The similarity of results confirmed in all three dimensions (Spearman correlation, density distributions and Li tests) is a remarkable result that confirms the reliability of the new Farrell cost cross-efficiency measure when ranking performance (when compared to its traditional constant returns to scale counterpart), and endorses its use under variable returns to scale (VRS), for which a well-defined standard analogue does not exist.

However, before we comment on this additional set of results under VRS, we stress that for the warehouse industry, overall cost (in)efficiency can be almost equally blamed on faulty technical and allocative performance, with the latter having a marginally higher weight. While average technical efficiency is 0.484 , allocative efficiency is 0.582 . The median values being 0.411 and 0.605 , respectively. We remark once again that this interpretation of cross-efficiency in economic terms, and its decomposition into both sources, as presented in (22), were unavailable until now. Finally, focusing still on the results under constant returns to scale, a second conclusion emerges. Despite the high similarly, the existence of large numerical differences at the individual level between the economic and standard cross-efficiency measures (in favor of the former as stated in Proposition 1, $\left.\operatorname{CITE}_{c}\left(X_{l}, Y_{l}\right) \leq F C E_{c}\left(X_{l}, Y_{l}\right)\right)$ suggest that the warehouse production technology is non-homothetic. Indeed, according to Theorem 1, $\operatorname{CITE}_{c}\left(X_{l}, Y_{l}\right)=F_{C E}\left(X_{l}, Y_{l}\right)$ under input homotheticity, and therefore these disparities rule out its existence.

We comment now on the new economic cross-efficiency measure under variable returns to scale, $F C E_{v}\left(X_{l}, Y_{l}\right)$, presented on the right hand side of Table 2. An immediate critic that can be raised against it is that it does not solve that the lack of discriminatory power of the standard Farrell input measure when observations are efficient: i.e., $\operatorname{ITE}_{c}\left(X_{l}, Y_{l}\right)=1$. We can qualify this drawback of the new measure by remarking that as many as 37 warehouses are efficient under $\operatorname{VRS}\left(36.3 \%\right.$ of the sample), while only 10 warehouses exhibit $F C E_{v}\left(X_{l}, Y_{l}\right)=1(9.8 \%)$-we also stress the fact that it is a well-defined measure not prone to negative values as the standard technical cross-efficiency under VRS. Hence, while full cost cross-efficiency under VRS is a feasible result likely to be observed (as opposed to its CRS counterpart $F C E_{c}\left(X_{l}, Y_{l}\right)$ ), its calculation is still quite useful from a managerial perspective, as it substantially increases discrimination among observation that are VRS efficient. As for the sources of cost (in)efficiency when decomposing $F_{C E}\left(X_{l}, Y_{l}\right)$ according to (22), we note that the characterization of the reference technology by VRS does not change the relative weights of technical and allocative efficiencies, although the higher weight of the latter is now reversed. The average and median values of the technical efficiency are now 0.662 and 0.622 , on a par with allocative efficiency whose values are 0.631 and 0.606 , respectively. 
One can compare the new Farrell cost cross-efficiencies calculated under both constant and variable returns to scale, i.e., $F C E_{c}\left(X_{l}, Y_{l}\right)$ vs. $\operatorname{FCE}_{v}\left(X_{l}, Y_{l}\right)$, but the exercise requires further assumptions about the market structure. Generally only the technical side of the economic performance would have a valid interpretation as the usual measure of scale efficiency, defined as $\operatorname{ITE}_{c}\left(X_{l}, Y_{l}\right) / \operatorname{ITE}_{v}\left(X_{l}, Y_{l}\right)$. The notion of a cost function defined under the restrictive case of constant returns to scale does not have any justification if the technology exhibits variable returns to scale or, from a weaker perspective, is non-homothetic. This is indeed the case for the usual DEA characterization of the production technologies, as in the current warehouse application-recalling Aparicio et al. (2015, 887; Proposition 3), these authors show that in the restrictive case of a single output and CRS, the technology is homothetic. Since virtually in all empirical applications the technology is characterized by VRS, our newly proposed Farrell cost cross-efficiency exhibits its full potential in its VRS definition (on top of its ability to provide an analytical framework that excludes negative values). Hence, the CRS definition of the Farrell cost cross-efficiency, $\operatorname{FCE}_{c}\left(X_{l}, Y_{l}\right)$ (equal to its traditional counterpart $\operatorname{CITE}_{c}\left(X_{l}, Y_{l}\right)$ under input homotheticity), from which our paper starts out theoretically, is only relevant for pedagogical purposes, presented so as to reinterpret the existing CRS (technical) cross efficiency measures in economic terms and, later on, move on to introduce the (empirically) relevant VRS definitions of (21) and (22), i.e., $F C E_{v}\left(X_{l}, Y_{l}\right)$.

The only exception that would grant the assumption of CRS in studies where a distinct market structure can be considered, is the theoretical consideration of the perfectly competitive long run equilibrium, where the technology exhibits CRS, industry profits are zero and average cost is minimum, by definition. In this case, the difference between $F C E_{v}\left(X_{l}, Y_{l} \mid k\right)$ and $F C E_{c}\left(X_{l}, Y_{l} \mid k\right)$, compares the performance corresponding to the current short run situation (normally associated with a suboptimal scale size if scale inefficiency exists), and the hypothetical long run equilibrium—both measures evaluated at their respective optimal prices, $\left(V_{k}^{*}, U_{k}^{*}\right)$. Arguably, the warehouse industry departs from the perfectly competitive framework in many ways, but if one were willing to assume it, then the comparison between the average values corresponding to $F C E_{v}\left(X_{l}, Y_{l}\right)$ and $F C E_{c}\left(X_{l}, Y_{l}\right)$ shows that the difference between both measures is noticeable, i.e., 0.443 and 0.233 (with a similar gap at the median). As for the ranking compatibility, it is relatively high: $\rho\left(F C E_{c}\left(X_{l}, Y_{l}\right), F C E_{v}\left(X_{l}, Y_{l}\right)\right)=0.720$, also significant at the $1 \%$ level. However, in Figure 2 the kernel density functions between the two follow different patterns with lower and higher density values for $F C E_{v}\left(X_{l}, Y_{l}\right)$ in the lower and upper tails, respectively. As seen in Table 3, this translates in a Li test result (2.056) that rejects the null hypothesis that both distributions are the same. Therefore, as expected, scale efficiency would play a big part in the assessment of 
performance through the new economic efficiency measures, under alternative assumptions of market structures. ${ }^{2}$

\subsection{Nerlovian economic (profit) cross-inefficiency}

Table 4 presents our second set of results on to the new Nerlovian profit cross-inefficiency measure based on the profit function and its duality with the directional distance function; i.e., expression (30). As normally assumed in the empirical literature we consider that the directional vector corresponds to the observed input and output quantities: $\left(G_{k}^{x}, G_{k}^{y}\right)=\left(X_{k}, Y_{k}\right), k=1, \ldots, n$. Following the presentation in the theoretical section, we start our discussion considering the results obtained under the assumption of variable returns to scale. The first conclusion worth highlighting is that the ability to discriminate among VRS efficient observations is complete. Although once again a large set of warehouses are deemed efficient, with $\vec{D}_{v}\left(X_{l}, Y_{l} ; X_{l}, Y_{l}\right)=0$ (43, representing $42.2 \%$ of the sample), none of them are cross-efficient from an economic perspective: i.e., $\operatorname{NCI}_{v}\left(X_{l}, Y_{l} ;\left\{X_{k}, Y_{k}\right\}_{k=1}^{n}\right)>0 .{ }^{3}$ Consequently, the above criticism against the Farrell economic cross-efficiency measure cannot be raised on this occasion. This result also suggests that Nerlovian profit inefficiency, once the input and output dimensions are taken into consideration, is larger than in the Farrell case where inefficiency refers only to the input (cost) dimension.

Ultimately, the obtained Nerlovian cross-inefficiency values bear proof of the fact that, again for the first time, our model can effectively rank observations by appraising their profit performance against all remaining peers under VRS. Moreover, it is possible to decompose this relative economic performance following expression (30). The descriptive statistics show that the sources of Nerlovian profit cross-inefficiency substantially change with respect to those of the Farrell's cost approach. The average profit cross-inefficiency amounts 0.666 , but now average technical inefficiency is a meager 0.102 , while allocative inefficiency is 0.562 ; representing $15.3 \%$ and $84.7 \%$ of the overall profit inefficiency, respectively.

\footnotetext{
${ }^{2}$ We conclude this subsection commenting on the disparity between $F C E_{v}\left(X_{l}, Y_{l}\right)$ and the standard technical cross-efficiency measure $\operatorname{CITE}_{c}\left(X_{l}, Y_{l}\right)$, rather than $\operatorname{FCE}_{c}\left(X_{l}, Y_{l}\right)$. The Li test, with a statistic equal to 6.257 , also returns that both distributions are statistically different, as can be confirmed by visually inspecting them in Figure 2. This result simply reinforces the previous one, i.e., between $F C E_{v}\left(X_{l}, Y_{l}\right)$ and $F_{C E}\left(X_{l}, Y_{l}\right)$, as $\operatorname{CITE}_{c}\left(X_{l}, Y_{l}\right)$ would be equal to the latter under input-homotheticity. Hence the numerical difference between both tests (columns 3 and 4 in Table 3), can be associated to the existence of a non-homothetic technology.

${ }^{3}$ For additive measures, the greater the score the higher the inefficiency; hence the change in denomination.
} 
Table 4. Nerlovian profit cross-inefficiency decomposition $N_{C I}\left(X_{l}, Y_{l} ;\left\{G_{k}^{x}, G_{k}^{y}\right\}_{k=1}^{n}\right)$. Expression (30), $T \in\{c, v\},-$ CRS and VRS, respectively.

\begin{tabular}{|c|c|c|c|c|c|c|c|c|}
\hline \multirow[b]{2}{*}{ Ranking } & \multicolumn{4}{|c|}{ Variable Returns to Scale, VRS (DDF model, $\left(G_{k}^{x}, G_{k}^{y}\right)=\left(X_{k}, Y_{k}\right)$ ) } & \multicolumn{4}{|c|}{ Constant Returns to Scale, CRS (DDF model, $\left(G_{k}^{x}, G_{k}^{y}\right)=\left(X_{k}, Y_{k}\right)$ ) } \\
\hline & $\begin{array}{c}\text { Warehouse } \\
\quad \#\end{array}$ & $\begin{array}{c}\text { Standard DDF } \\
\vec{D}_{v}\left(X_{l}, Y_{l} ; X_{l}, Y_{l}\right) \\
(25) \\
\end{array}$ & $\begin{array}{c}\text { New Nerlovian } \\
\text { Cross-Ineffic. } \\
\operatorname{NCI}_{v}\left(X_{l}, Y_{l} ;\left\{X_{k}, Y_{k}\right\}_{k=1}^{n}\right) \\
(29) \\
\end{array}$ & $\begin{array}{c}\text { New Nerlovian } \\
\text { Alloc. Inefficiency } \\
N C I_{v}\left(X_{l}, Y_{l} ;\left\{X_{k}, Y_{k}\right\}_{k=1}^{n}\right) \\
-\vec{D}_{v}\left(X_{l}, Y_{l} ; X_{l}, Y_{l}\right) \\
(30)\end{array}$ & $\begin{array}{c}\text { Warehouse } \\
\quad \#\end{array}$ & $\begin{array}{c}\text { Standard DDF } \\
\vec{D}_{c}\left(X_{l}, Y_{l} ; X_{l}, Y_{l}\right) \\
(24) \\
\end{array}$ & $\begin{array}{c}\text { New Nerlovian } \\
\text { Cross Efficiency } \\
N C I_{c}\left(X_{l}, Y_{l} ;\left\{X_{k}, Y_{k}\right\}_{k=1}^{n}\right) \\
=C D D F_{c}\left(X_{l}, Y_{l}\right) \\
(32)\end{array}$ & $\begin{array}{c}\text { New Nerlovian } \\
\text { Alloc. Efficiency } \\
N C I_{c}\left(X_{l}, Y_{l} ;\left\{X_{k}, Y_{k}\right\}_{k=1}^{n}\right) \\
-\vec{D}_{c}\left(X_{l}, Y_{l} ; X_{l}, Y_{l}\right) \\
(34)\end{array}$ \\
\hline 1 & 50 & 0.000 & 0.176 & 0.176 & 50 & 0.000 & 0.112 & 0.112 \\
\hline 2 & 89 & 0.000 & 0.226 & 0.226 & 19 & 0.000 & 0.130 & 0.130 \\
\hline 3 & 34 & 0.000 & 0.250 & 0.250 & 49 & 0.000 & 0.181 & 0.181 \\
\hline 4 & 23 & 0.000 & 0.275 & 0.275 & 54 & 0.000 & 0.229 & 0.229 \\
\hline 5 & 25 & 0.000 & 0.280 & 0.280 & 33 & 0.000 & 0.272 & 0.272 \\
\hline 98 & 93 & 0.283 & 1.642 & 1.359 & 11 & 0.789 & 0.891 & 0.102 \\
\hline 99 & 13 & 0.199 & 1.678 & 1.479 & 12 & 0.734 & 0.898 & 0.164 \\
\hline 100 & 77 & 0.497 & 1.792 & 1.295 & 69 & 0.808 & 0.921 & 0.113 \\
\hline 101 & 75 & 0.250 & 1.981 & 1.731 & 65 & 0.816 & 0.944 & 0.128 \\
\hline 102 & 96 & 0.000 & 2.119 & 2.119 & 77 & 0.903 & 0.956 & 0.053 \\
\hline & Minimum & 0.000 & 0.176 & 0.176 & Minimum & 0.000 & 0.112 & 0.053 \\
\hline & Median & 0.045 & 0.550 & 0.444 & Median & 0.418 & 0.709 & 0.254 \\
\hline & Average & 0.102 & 0.666 & 0.564 & Average & 0.398 & 0.671 & 0.273 \\
\hline & Maximum & 0.568 & 2.119 & 2.119 & Maximum & 0.903 & 0.956 & 0.695 \\
\hline & Stand. Dev. & 0.140 & 0.390 & 0.350 & Stand. Dev. & 0.259 & 0.187 & 0.140 \\
\hline
\end{tabular}


As recalled on expression (33), if constant returns to scale were assumed, the new Nerlovian profit cross-inefficiency coincides with the technical cross-inefficiency measure proposed by Ruiz (2013): $\operatorname{NCI}_{c}\left(X_{l}, Y_{l} ;\left\{X_{k}, Y_{k}\right\}_{k=1}^{n}\right)=\operatorname{CDDF}_{c}\left(X_{l}, Y_{l}\right)$. However, as previously discussed, the economic re-interpretation of the (technical) directional cross-efficiency under CRS would not be adequate unless its assumption is granted by the existence of a perfectly competitive market structure framed in the long run. In that case, although the average levels of profit crossinefficiency are very similar, $N C I_{v}\left(X_{l}, Y_{l} ;\left\{X_{k}, Y_{k}\right\}_{k=1}^{n}\right)=0.666$ vs. $N C I_{c}\left(X_{l}, Y_{l} ;\left\{X_{k}, Y_{k}\right\}_{k=1}^{n}\right)=0.671$, its sources greatly differ since now technical and allocative inefficiencies represent $59.4 \%$ and $40.7 \%$ of the overall inefficiency. Despite the similar average values, the rank correlation between both series is relatively low at $\rho\left(N C I_{v}\left(X_{l}, Y_{l} ;\left\{X_{k}, Y_{k}\right\}_{k=1}^{n}\right), N C I_{c}\left(X_{l}, Y_{l} ;\left\{X_{k}, Y_{k}\right\}_{k=1}^{n}\right)\right)=$ 0.285 - significant at the $1 \%$ level, and implying that the choice of returns to scale is even more relevant when assessing industry performance than in the Farrell case. The disparity between both sets of results can be seen in Figure 3, where the density of the CRS results peaks around one (rather than 0.5 under VRS), followed by its sudden fall and disappearance because no values beyond this threshold are observed. It comes, then, as no surprise that the associated Li test comparing $\operatorname{NCI}_{v}\left(X_{l}, Y_{l} ;\left\{X_{k}, Y_{k}\right\}_{k=1}^{n}\right)$ and $C D D F_{c}\left(X_{l}, Y_{l}\right)$ (with a Li statistic equal to 15.245) rejects the null hypothesis of equality of distributions.

Figure 3. Estimated kernel density distributions of the new Nerlovian economic crossinefficiency, $N C I_{v}\left(X_{l}, Y_{l} ;\left\{X_{k}, Y_{k}\right\}_{k=1}^{n}\right)-(29)$, and the standard cross-inefficiency, $C D D F_{c}\left(X_{l}, Y_{l}\right)-(32)$.

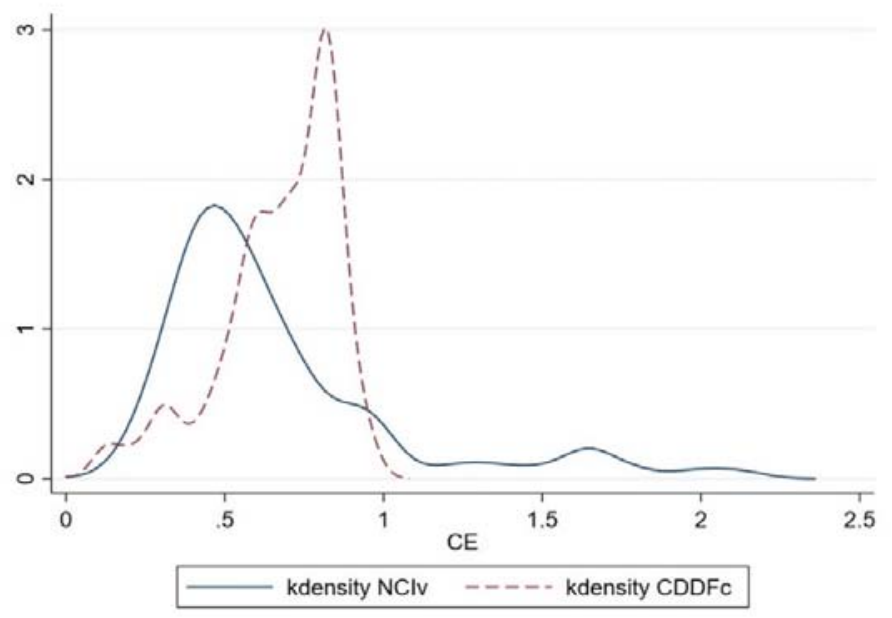




\section{Summary and Conclusions}

Despite the capability of cross-efficiency to yield a suitable ranking of observations based on the (shadow) prices associated with all the sample units when evaluating each observation, these techniques have developed without establishing any connection with the literature devoted to measuring economic efficiency when prices are present; i.e., relying on microeconomic theory. This paper makes the connection between the concepts of economic efficiency and crossefficiency. Economic cross-(in)efficiency measures the performance of observations in terms of a set of reference prices that could correspond to either market prices, shadow prices or any other imputed prices. Hence, this economic cross-efficiency measure can be interpreted as the capability of firms to behave optimally by reaching minimum cost or maximum profit for a wide range of prices. The new methodology is particularly relevant in studies where market prices are not readily available because of the institutional framework (e.g., public services such as education, health, safety, etc.), but yet a robust ranking of observations based on their performance is demanded by decision makers and stakeholders.

Within the DEA framework we show that, under input homotheticity, the traditional bilateral notion of input cross-efficiency for unit $l$, when the weights of unit $k$ are used in the evaluation, coincides with the well-known Farrell notion of cost efficiency for unit $l$ when precisely unit $k$ weights are taken as market prices. However, this result does not hold if the technology is not input homothetic. This motivates the introduction of the concept of bilateral Farrell cost crossefficiency (FCE), corresponding to his notion of cost efficiency under either constant or variable returns to scale. We also extend this proposal based on the classic Farrell framework restricted to the input dimension to more recent developments corresponding to a complete representation of the economic objective of the firms through the profit function, and its dual characterization by way of the flexible directional distance function. This results in the introduction of the parallel concept of Nerlovian (profit) cross-inefficiency (NCI). In both cases, either à la Farrell or à la Nerlove, the new analytical framework allows us to further exploit the duality properties of the economic measures and decompose economic cross-(in)efficiency according to technological and allocative criteria.

We emphasize that a key advantage of the Farrell and Nerlovian cross-(in)efficiency measures is that they are well defined under variable returns to scale (VRS) by yielding scores that always lay between zero and one for the former and are always greater than zero for the latter. This solves a well-known weakness of the standard cross-efficiency methods, which may result in negative scores when the technology is characterized by VRS. The economic cross-(in)efficiency methodology solves this problem in a natural way, without proposing ad-hoc methods such as those based on data translations (e.g., Lim and Zhu, 2015). 
We illustrate the new models and associated measures using a recently compiled data set of European warehouses. We show that the economic cross-efficiency measures FCE and NCI are well defined under constant and variable returns to scale, and how they can be decomposed according to technical and allocative criteria. Moreover, the large rank correlation between the standard cross-efficiency values and the new Farrell cost cross-efficiency under constant returns to scale, suggests that these latter model can be extended to variable returns to scale with confidence. We compare the constant and variable returns to scale measures, and conclude through the visual inspection of their kernel density functions and associated Li tests that assuming alternative returns to scale does make a difference in the evaluation of economic performance, since results are statistically different. This is a remarkable conclusion because the numerical differences between the constant and variable returns to scale measures signal that warehouse operations are characterized by non-homothetic technologies (i.e., Theorem 1 does not hold), which further justifies the introduction of the new economic cross-efficiency models under variable returns and reinforces their use in empirical applications. How to interpret the difference between both sets of results in economic terms is harder than in the technological case associated to scale (in)efficiency, because different assumptions regarding the market structure need to be brought into the analysis (e.g., perfectly or imperfectly competitive markets, and long and shortrun equilibria).

Next we identify some avenues for further follow-up research. First, we resorted in this paper to two specific approaches for measuring economic efficiency, and transpose them to the realm of what we term economic cross-efficiency evaluation. However, it seems natural to apply other alternative approaches like, for example, those related to the hyperbolic measure (Färe et al. 2002, and Zofío and Prieto, 2006) or the weighted additive model (Cooper et al., 2011, and Aparicio et al., 2016). Second, there are contributions in the literature that study the measurement and decomposition of economic efficiency change over time when panel data are available (see, for example, Maniadakis and Thanassoulis, 2004, and Juo et al., 2015). A natural extension of the current paper would result in a model measuring how economic cross-efficiency rankings change over time. Third, there does not exist a notion of cross-efficiency in the parametric approach to efficiency analysis, where cost functions, for example, are estimated once a functional form has been specified, and depending on a set of parameters that must be estimated. In this respect, the introduced Farrell cost cross-efficiency measure could be determined parametrically, constituting a first application of cross-efficiency in the parametric framework for efficiency measurement. Fourth, one difficulty with traditional cross-efficiency evaluation is the possible existence of alternative optima in the DEA models providing the weights (first stage), resulting in different cross-efficiency scores (second stage). The approach that has been traditionally followed to address this issue is based on the use of secondary goals as criteria to choose a given set of weights 
among the alternative optimal solutions. The well-known benevolent and aggressive approaches proposed in Sexton et al. (1986) and Doyle and Green (1994) are among the most popular ones. All these proposals are relevant qualifications and natural extensions that would result in the consolidation and improvement of the new concept of economic cross-efficiency.

\section{Acknowledgements}

Authors acknowledge the financial support from the Spanish Ministry for Economy and Competitiveness (Ministerio de Economía, Industria y Competitividad), the State Research Agency (Agencia Estatal de Investigación) and the European Regional Development Fund (Fondo Europeo de Desarrollo Regional) under grant MTM2016-79765-P (AEI/FEDER, UE). Authors thank Magdalena Kapelko for assisting in the calculation of the Li tests at the Wroclaw Centre for Networking and Supercomputing (www.wcss.wroc.pl), grant no. 286. 


\section{References}

Aldamak, A., \& Zolfaghari, S. (2017). Review of efficiency ranking methods in data envelopment analysis. Measurement, 106, 161-172.

Aparicio, J., Pastor, J. T., \& Zofio, J. L. (2015). How to properly decompose economic efficiency using technical and allocative criteria with non-homothetic DEA technologies. European Journal of Operational Research, 240(3), 882-891.

Aparicio, J., Pastor, J. T., \& Vidal, F. (2016). The weighted additive distance function. European Journal of Operational Research, 254(1), 338-346.

Aparicio, J. \& Zofío, J. L. (2017). Revisiting the decomposition of cost efficiency for nonhomothetic technologies: a directional distance function approach. Journal of Productivity Analysis, 48(2), 133-146.

Balk, B.M., de Koster, M.B.M., Kaps, C. \& Zofío, J.L. (2017). An Evaluation of Cross-Efficiency Methods, Applied to Measuring Warehouse Performance. ERIM Report Series Research in Management ERS-2017-015-LIS, Erasmus Research Institute of Management (ERIM), Erasmus University Rotterdam, The Netherlands.

Banker, R.D., Charnes, A. \& Cooper, W.W. (1984). Some models for estimating technical and scale inefficiencies in data envelopment analysis. Management Science, 30(9), 1078-1092.

Chambers, R.G., Chung, Y. \& Färe, R. (1998). Profit, directional distance functions and Nerlovian efficiency. Journal of Optimization Theory and Applications, 98 (2), 351-364.

Chambers, R. G., \& Mitchell, T. (2001). Homotheticity and non-radial changes. Journal of Productivity Analysis, 15(1), 31-39.

Charnes, A., Cooper, W.W. \& Rhodes, E. (1978). Measuring the efficiency of decision making units. European Journal of Operational Research, 2/6, 429-444.

Cook, W. D., \& Zhu, J. (2015). DEA cross efficiency. In Data envelopment analysis (pp. 23-43). Springer, Boston, MA.

Cooper, W. W., Pastor, J. T., Aparicio, J., \& Borras, F. (2011). Decomposing profit inefficiency in DEA through the weighted additive model. European Journal of Operational Research, 212(2), 411-416.

De Koster, M. B. M. \& Balk, B. M. (2008). Benchmarking and monitoring international warehouse operations in Europe. Production and Operations Management, 17, 175-183.

Doyle, J., \& Green, R. (1994). Efficiency and cross-efficiency in DEA: Derivations, meanings and uses. Journal of the Operational Research Society, 45(5), 567-578. 
Färe, R. \& Primont, D. (1995). Multi-Output Production and Duality: Theory and Applications, Kluwer Academic.

Färe, R., Grosskopf, S., \& Zaim, O. (2002). Hyperbolic efficiency and return to the dollar. European Journal of Operational Research, 136(3), 671-679.

Farrell, M.J. (1957). The measurement of productive efficiency. Journal of the Royal Statistical Society, Series A, General, 120, 253-281.

Jablonsky, J. (2018). Ranking of countries in sporting events using two-stage data envelopment analysis models: a case of Summer Olympic Games 2016. Central European Journal of Operations Research, 1-16.

Jacobsen, S. E. (1970). Production correspondences. Econometrica, 38(5), 754-768.

Johnson, A. \& McGinnis, L. F. (2011). Performance measurement in the warehousing industry. IIE Transactions, 43, 220-230.

Juo, J. C., Fu, T. T., Yu, M. M. \& Lin, Y. H. (2015). Profit-oriented productivity change. Omega, 57, 176-187.

Li, Q. (1996). Nonparametric testing of closeness between two unknown distribution functions. Econometric Reviews, 15: 261-274.

Lim, S. \& Zhu, J. (2015). DEA cross-efficiency evaluation under variable returns to scale. Journal of the Operational Research Society, 66(3), 476-487.

Lovell, C.K., Grosskopf, S., Ley, E., Pastor, J.T., Prior, D. \& Eeckaut, P.V. (1994). Linear programming approaches to the measurement and analysis of productive efficiency. Top, 2(2), $175-248$.

Luenberger, D. G. (1992). New optimality principles for economic efficiency and equilibrium. Journal of optimization theory and applications, 75(2), 221-264.

Maniadakis, N., \& Thanassoulis, E. (2004). A cost Malmquist productivity index. European Journal of Operational Research, 154(2), 396-409.

Petersen, N. C. (2018). Directional Distance Functions in DEA with Optimal Endogenous Directions. Operations Research, 66(4), 1068-1085.

Rosenthal, E. C., \& Weiss, H. J. (2017). A data envelopment analysis approach for ranking journals. Omega, 70, 135-147.

Ruiz, J. L. (2013). Cross-efficiency evaluation with directional distance functions. European Journal of Operational Research, 228(1), 181-189. 
Ruiz, J. L., \& Sirvent, I. (2016). Ranking decision making units: The cross-efficiency evaluation. In Handbook of operations analytics using data envelopment analysis (pp. 1-29). Springer, Boston, MA.

Sheather, S. \& Jones, M. (1991). A reliable data-based bandwidth selection method for kernel density estimation. Journal of the Royal Statistical Society. Series B, 53: 683-690.

Silverman, B. W. (1986). Density Estimation for Statistics and Data Analysis. London: Chapman and Hall.

Simar, L. \& Zelenyuk, V. (2006). On testing equality of distributions of technical efficiency scores. Econometric Reviews, 25(4): 497-522.

Sexton, T. R., Silkman, R. H., \& Hogan, A. J. (1986). Data envelopment analysis: Critique and extensions. In R. H. Silkman (Ed.), Measuring efficiency: An assessment of data envelopment analysis (pp. 73-105). San Francisco: Jossey-Bass.

Shephard, R.W. (1953). Cost and Production Functions. Princeton Univ. Press.

Wu, J., Liang, L., \& Chen, Y. (2009). DEA game cross-efficiency approach to Olympic rankings. Omega, 37(4), 909-918.

Zofío, J. L., \& Prieto, A. M. (2006). Return to dollar, generalized distance function and the Fisher productivity index. Spanish Economic Review, 8(2), 113-138. 